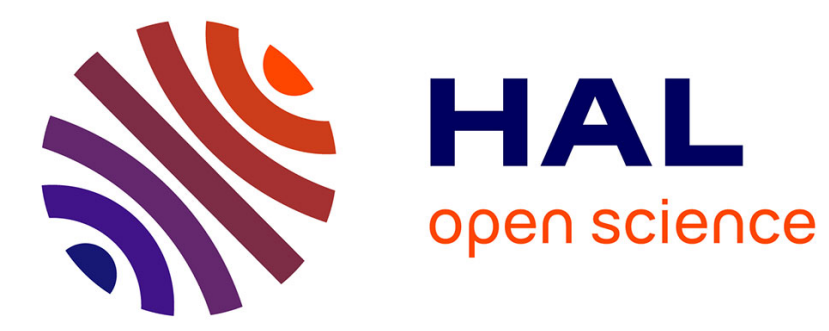

\title{
Bio-Based Aliphatic Polyurethanes Through ADMET Polymerization in Bulk and Green Solvent
}

Thomas Lebarbé, Arvind S. More, Prakash Sudhir Sane, Etienne Grau, Carine Alfos, Henri Cramail

\section{- To cite this version:}

Thomas Lebarbé, Arvind S. More, Prakash Sudhir Sane, Etienne Grau, Carine Alfos, et al.. Bio-Based Aliphatic Polyurethanes Through ADMET Polymerization in Bulk and Green Solvent. Macromolecular Rapid Communications, 2014, 35 (4), pp.479-483. 10.1002/marc.201300695 . hal-01366323

\section{HAL Id: hal-01366323 \\ https://hal.science/hal-01366323}

Submitted on 26 Nov 2019

HAL is a multi-disciplinary open access archive for the deposit and dissemination of scientific research documents, whether they are published or not. The documents may come from teaching and research institutions in France or abroad, or from public or private research centers.
L'archive ouverte pluridisciplinaire HAL, est destinée au dépôt et à la diffusion de documents scientifiques de niveau recherche, publiés ou non, émanant des établissements d'enseignement et de recherche français ou étrangers, des laboratoires publics ou privés. 


\title{
Bio-Based Aliphatic Polyurethanes Through ADMET Polymerization in Bulk and Green Solvent
}

Thomas Lebarbé, Arvind Sudhakar More, Prakash Sudhir Sane, Etienne Grau, Carine Alfos, Henri Cramail

\begin{abstract}
A new route to $\alpha, \omega$-diene urethane monomer is proposed by converting 10-undecenoic acid into the corresponding acyl azide, followed by urethanization with 10-undecenol. ADMET polymerizations of this $\alpha, \omega$ diene urethane monomer as well as other bio-based $\alpha, \omega$-dienes bearing various organic functions (ester, carbonate, ether, amide) were carried out in bulk and solution conditions. A screening of the most commonly used metathesis catalysts allows to evaluate their tolerance toward the urethane function as well as toward Polarclean, a "green" and nontoxic high boiling point solvent. The influence of the nature of the central organic function in these $\alpha, \omega$-diene monomers on the thermomechanical properties is investigated.
\end{abstract}

\section{Introduction}

Polyurethanes are among the most important polymeric materials with about $6 \%$ of the world plastic use.1 In the last decade, many attempts have been carried out to develop greener routes to renewable polyurethanes. More particularly vegetable oils have gained high importance in that field due to their availability, sustainability, and their relatively low cost. A lot of investigations were carried out to design new aliphatic polyols for the traditional synthesis of polyurethanes networks and thermoplastics.2-4 Despite the low toxicity and the renewable character of these new bio-based polyols, diisocyanate synthesis still remains an issue regarding the commonly use of phosgene as carbonation agent and the toxicity of isocyanates.

In our effort to propose various pathways for polyurethane synthesis,5-7 we recently investigated acyclic diene metathesis (ADMET) polymerization for designing new bio-based aliphatic polyurethanes. Indeed, the emergence of highly tolerant metathesis catalysts in the 1990s enabled the use of functional monomers and afforded new pathways to various polymeric systems.8, 9 ADMET polymerization was already reported for the synthesis of fatty acid-based polyesters, polyamides, polyethers, and polycarbonates10-14 but, to the best of our knowledge, not for bio-based polyurethanes.

Here, we used 10-undecenoic acid platform as it is obtained by a two-step process from castor oil, a readily available annual plant seed oil.15 In continuation to recent investigations, we performed concerning $A B$-type self-condensation of hydroxyacyl azide,5, 7 and due to the efficiency and simplicity of the acyl-azide route for the formation of masked isocyanate, this approach was retained for the synthesis of $\alpha, \omega$-diene urethane.

\section{Results and Discussion}

\subsection{Synthesis of the Novel Urethane Monomer}

Prior to polymerizations study, a two-step methodology was applied for the synthesis of the urethane monomer (Figure 1). First, 10-undecenoic acid was reacted with ethyl chloroformate in the presence of triethylamine to 
form in situ anhydride, which then reacted with sodium azide to obtain the acyl-azide compound. Completion of the reaction was monitored by FTIR-ATR (Figure S1, Supporting Information). The spectrum revealed the appearance of bands at 1720,2120 , and $2300 \mathrm{~cm}^{-1}$, which are attributed to acyl azide $\mathrm{C}=\mathrm{O}$ stretching, $\mathrm{N}_{3}$ bending, and isocyanate $\mathrm{N}=\mathrm{C}=\mathrm{O}$ stretching modes. This analysis shows that a small fraction of the acyl-azide intermediate rearranged into the isocyanate compound (26\%) by a Curtius rearrangement. It was also confirmed by ${ }^{1} \mathrm{H} N M R$ spectroscopy with the appearance of a signal at $3.28 \mathrm{ppm}$ related to protons near the isocyanate group (Figure $\mathbf{2}$ ). However, the presence of isocyanate functions is not an issue as the latter will be also converted in the second step to the expected urethane.

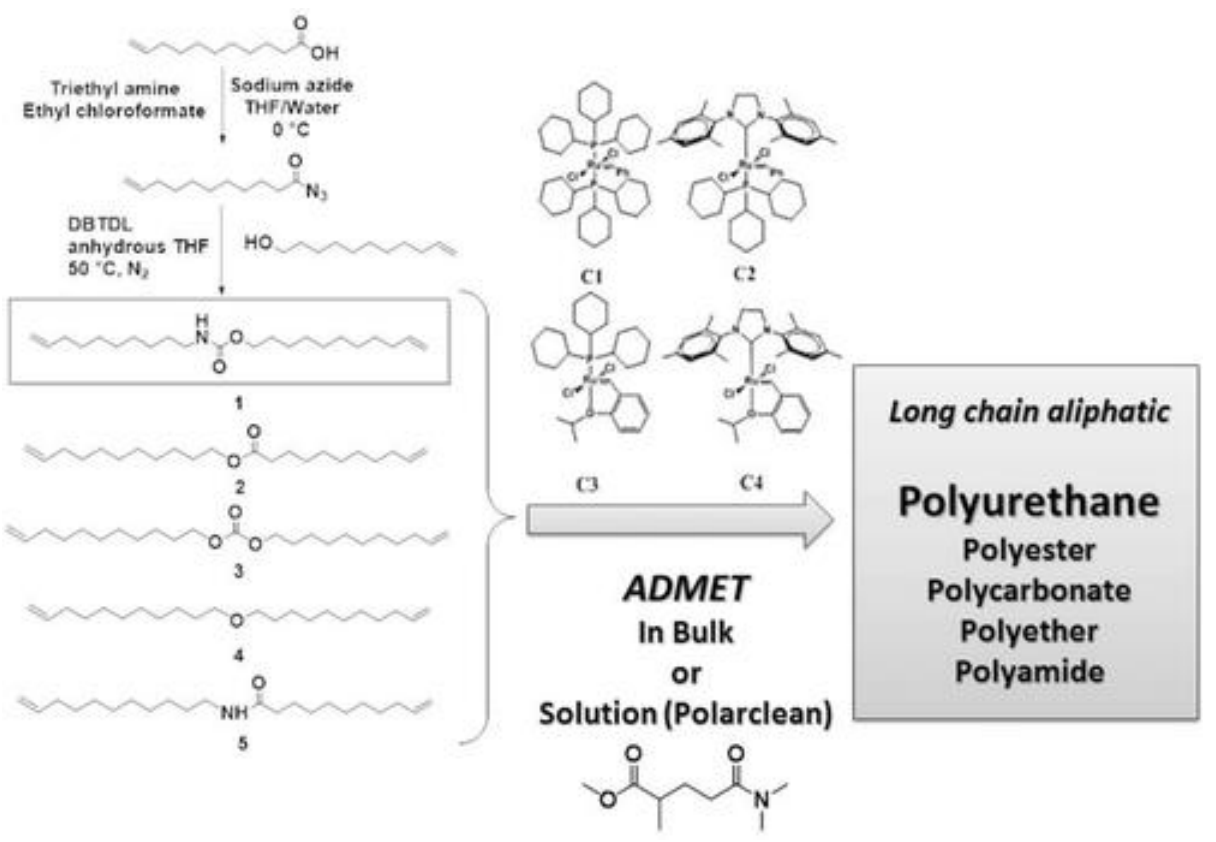

Figure 1 Structure of the monomers and the catalysts used in this study.

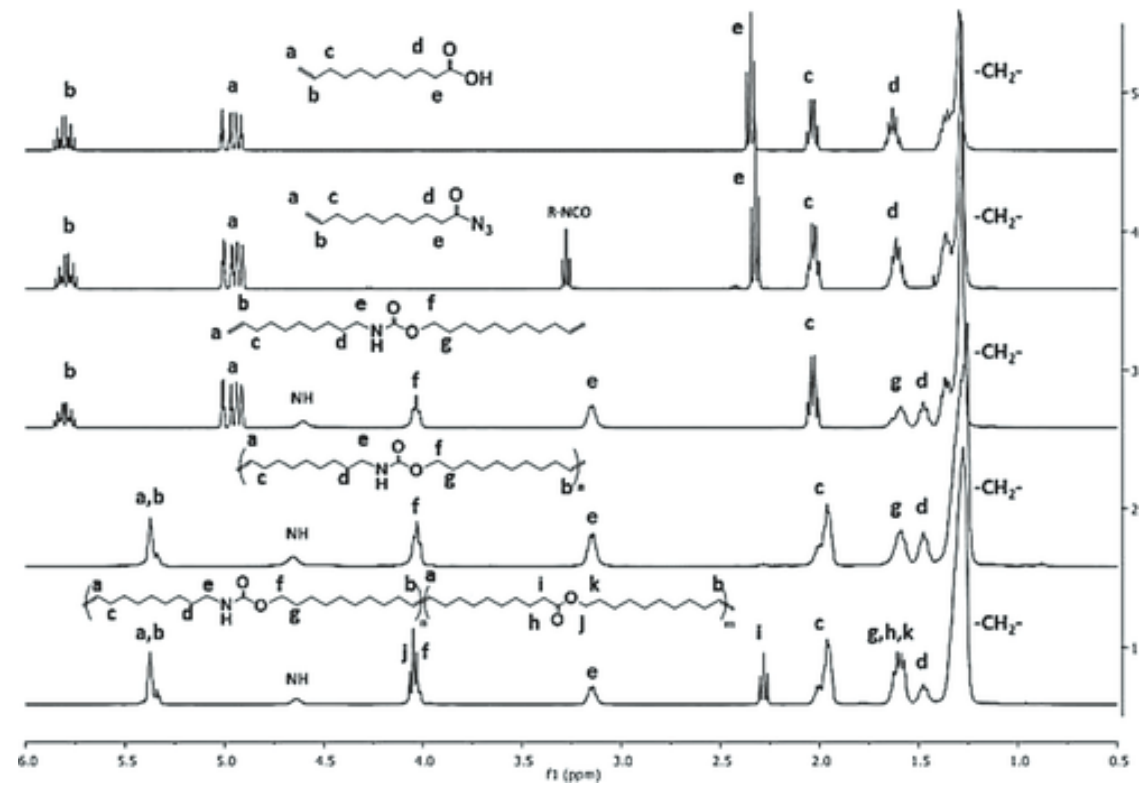

Figure $2{ }^{1} \mathrm{H}$ NMR stacked spectra in $\mathrm{CDCl}_{3}$ of the molecules at different steps of the synthesis of polyurethane and poly(ester-urethane). 
The $\alpha, \omega$-diene urethane monomer (1) was then obtained by Curtius rearrangement with 10-undecenol. Its structure was confirmed by FTIR-ATR analysis (Figure S1, Supporting Information) as well as NMR spectroscopy (Figure 2; Figure S2-S4, Supporting Information). FTIR spectrum of (1) displays one band at $1700 \mathrm{~cm}^{-1}$ related to the $\mathrm{C}=\mathrm{O}$ stretching of urethane function and a broad band at $3300 \mathrm{~cm}^{-1}$ related to $\mathrm{NH}$ bending. Regarding ${ }^{1} \mathrm{H}$ NMR spectrum of (1), neither acyl azide nor isocyanate has been observed after purification. New peaks appeared at $3.08,3.97$, and $4.54 \mathrm{ppm}$ that are assigned, respectively, to the protons in $\alpha$ position of the urethane linkage as well as to the proton attached to the nitrogen atom.

\subsection{Tolerance Investigation of the Catalysts Toward Polarclean Solvent}

(1) was subjected to ADMET polymerization. ADMET is generally conducted in bulk when the melting points of both monomers and polymers are not too high $\left(<100^{\circ} \mathrm{C}\right)$. In the case of ADMET in solution, a high boiling point solvent is generally needed to fit with the reaction conditions (temperature around $80^{\circ} \mathrm{C}$ with dynamic vacuum to eliminate the ethylene condensate). Solvents such as o-xylene or DMF fulfill the ADMET requirements, while their relative toxicity limit their use. Methyl-5-(dimethylamido)-2-methyl-5-oxopentanoate (Polarclean) is an eco-friendly water-soluble and polar solvent, which presents a high boiling point and a lower toxicity than oxylene or DMF.16 Moreover, this solvent can be easily removed from the reaction mixture by washing with methanol or water.

To our knowledge, Polarclean was never employed in metathesis reactions. The first step was thus to evaluate the tolerance of frequently used ruthenium-based metathesis catalysts toward Polarclean. To that aim, a previously reported $\alpha, \omega$-diene ester monomer (2)11 was synthesized (see Figures S5 and S6, Supporting Information) and used as a model in ADMET polymerizations.

(2) was first reacted in bulk with Grubbs 1st (C1), Grubbs 2nd (C2), Hoveyda-Grubbs 1st (C3), and HoveydaGrubbs 2nd (C4) generation catalysts. In all cases, the monomer feed was reacted with 0.5 mol\% of catalyst at $80^{\circ} \mathrm{C}$ for $24 \mathrm{~h}$ under dynamic vacuum. When $\mathbf{C 2}$ and $\mathbf{C} 4$ were used, $5 \mathrm{~mol} \%$ of $p$-benzoquinone was added to limit isomerization.17, 18 As expected, for all the reactions launched in bulk, good molecular weights were obtained, suggesting good tolerance of the catalysts toward the ester monomer (Table 1, entries $5^{\mathrm{a}}-8^{\mathrm{a}}$ ). Interestingly, despite their lower reactivity in comparison to 2 nd generation catalysts, 1 st generation catalysts led to higher molecular weights. It was ascribed to limited isomerization with these catalysts. Isomerization lowers the degree of polymerization due to less-volatile side products than ethylene gas, which cannot be removed from the reaction mixture. 
Table 1. Macromolecular characteristics of the polymers obtained by SEC in THF-PS calibration

\section{$\mathrm{Mn}\left[\mathrm{g} \mathrm{mol}^{-1}\right]$ (Dispersity)}

\begin{tabular}{|c|c|c|c|c|}
\hline Entry & Monomer & Catalyst & Bulk(a) & Polarclean(b) \\
\hline 1 & 1 & C1 & $17100(1.7)$ & - \\
\hline 2 & & C2 & 9300 (1.6) & - \\
\hline 3 & & C3 & 22600 (1.9) & - \\
\hline 4 & & C4 & $25400(2.4)$ & $20500(1.6)$ \\
\hline 5 & 2 & C1 & $43700(1.9)$ & $1500(1.2)$ \\
\hline 6 & & C2 & $10800(1.7)$ & 1300 (1.1) \\
\hline 7 & & C3 & $37000(2.2)$ & $52600(1.8)$ \\
\hline 8 & & C4 & $15700(1.5)$ & $24900(1.5)$ \\
\hline 9 & $1+2$ & C4 & - & $28500(1.6)$ \\
\hline 10 & 3 & C4 & $34400(1.8)$ & $50800(1.6)$ \\
\hline 11 & 4 & C4 & nd & $3900(1.7)$ \\
\hline 12 & 5 & C4 & nd & nd \\
\hline
\end{tabular}

ADMET polymerizations of (2) in Polarclean in the same reaction conditions were then launched. In the case of $\mathbf{C 1}$ and $\mathbf{C 2}$ (Table 1, entries $5^{\mathrm{b}}$ and $6^{\mathrm{b}}$ ), only oligomers were achieved in low yields (around 20\%), suggesting poor tolerance of these catalysts for the Polarclean solvent. The use of $\mathbf{C 3}$ and $\mathbf{C 4}$ (Table 1, entries $\mathbf{7}^{\mathrm{b}}$ and $8^{\mathrm{b}}$ ) was much more adapted regarding the higher molecular weights obtained in comparison to the other catalysts. It is noteworthy that solution polymerization of (2) by using $\mathbf{C 3}$ and $\mathbf{C 4}$ gave a polyester of higher molecular weight than bulk polymerization. It is ascribed to higher homogenization of the reaction mixture. 


\subsection{Tolerance Investigation of the Catalysts Toward Urethane Function}

(1) was first polymerized in bulk while screening the metathesis catalysts to evaluate their tolerance toward the urethane function. As shown in Table $\mathbf{1}$ (entries $1^{\mathrm{a}}$ and $2^{\mathrm{a}}$ ), $\mathbf{C 1}$ led to higher molecular weight than $\mathbf{C 2}$. It can be correlated with the amount of isomerization, despite the presence of $p$-benzoquinone, more important in the case of the polymer synthesized with $\mathbf{C 2}$ as shown from the ${ }^{1} \mathrm{H}$ NMR spectrum (see the peaks between 0.8 and 1 ppm in Figure S7b, Supporting Information). Hoveyda-Grubbs 1st generation catalyst, (C3), yielded higher molecular weight polymer than C1. Finally, Hoveyda-Grubbs 2nd generation catalyst, (C4), yielded polyurethanes with comparable molecular weight than the ones obtained with C3. Interestingly, lower molecular weights were found in the case of bulk ADMET of (1) than for ADMET of (2), except for $\mathbf{C} 4$ that appears to be more relevant than the other catalysts. Consequently, we retained $\mathbf{C 4}$ as a catalyst in the following.

\subsection{Solution ADMET Polymerizations of (1) and Other $\alpha, \omega$-dienes}

(1) was then polymerized in Polarclean, which led to a homogeneous reaction mixture. SEC analysis in THF showed a molecular weight of $20500 \mathrm{~g} \mathrm{~mol}^{-1}$. The completion of the polymerization was confirmed by ${ }^{1} \mathrm{H}$ NMR spectroscopy as seen from the decrease in the integration of the terminal olefin protons and the appearance of a multiplet at $5.37 \mathrm{ppm}$ (Figure 2). All peaks were easily assigned except the chain ends, which should be terminal double bonds. The appearance of undesirable signals between 0.85 and $1.00 \mathrm{ppm}$ suggests that some isomerization reactions took place, even in the presence of 1,4-benzoquinone, and that chain ends may consist in methyl groups. The introduction of ester functions in the polyurethane backbone was also carried out by copolymerizing (1) and (2) in equimolar ratio, with $\mathbf{C 4}$ as a catalyst (Table 1, entry $\mathbf{9}^{\mathrm{b}}$ ). The obtained copolymer exhibited a Mn of $28500 \mathrm{~g} \mathrm{~mol}^{-1}$ by SEC analysis with a dispersity of 1.6. Chemical composition of the copolymer, calculated from ${ }^{1} \mathrm{H}$ NMR analysis (Figure 2 ), was in agreement with the feed ratio.

To extend the palette of monomers polymerized through ADMET and obtained from 10-undecenoic acid platform, other bio-based $\alpha, \omega$-diene monomers bearing various organic functions were investigated. Monomers bearing carbonate (3)19 (Figures S8 and S9, Supporting Information), ether (4)20 (Figures S10 and S11, Supporting Information), and amide function (5) (Figure S12, Supporting Information) were synthesized and polymerized. ADMET polymerizations of (3), (4), and (5) were first conducted in bulk by using C4 as a catalyst (Table 1, entries $10^{\mathrm{a}}-12^{\mathrm{a}}$ ). An obvious increase of the viscosity of the reaction mixture was noticed in all cases; however, the polyamide and the polyether so-formed were insoluble in all the solvents generally used for SEC and NMR analysis, impeding their molecular characterization. The SEC analysis of the polycarbonate in THF showed a Mn of $34400 \mathrm{~g} \mathrm{~mol}^{-1}$ with a dispersity of 1.8. Polymerizations in Polarclean were then launched and showed evidence of polymer formation in all cases. The polycarbonate, analyzed by SEC in THF, presented a $\mathrm{Mn}$ of $50800 \mathrm{~g} \mathrm{~mol}^{-1}$, which is significantly higher than in bulk. Unlike the solution polymerizations of (1), (2), and (3), where the reaction mixtures were homogeneous, the polymerizations of (4) and (5) led to the precipitation of the polymers in Polarclean after a certain reaction time. Contrary to the polyether formed in bulk, the one synthesized in solution showed good solubility in THF, thus allowing its molecular characterization. A low $\mathrm{Mn}$ value of $3900 \mathrm{~g} \mathrm{~mol}^{-1}$ was measured, which explains the better solubility in THF. This low molecular 
weight was ascribed to the precipitation of the polymer in Polarclean during its formation, which limited the accessibility of the reactive sites. The polyamide was still not soluble in THF.

To summarize, Polarclean was revealed to be an effective solvent for ADMET polymerizations of (1), (2), and (3), while it does not dissolve properly the polymers resulting from (4) and (5).

\subsection{Influence of Organic Functions on the Properties of the Resulting Polymers}

Due to variations in the homogeneity of the reaction mixture during solution polymerizations, thermal investigations by DSC and TGA were performed with the polymers synthesized in bulk. Various thermal and thermomechanical behaviors were observed depending on the type of organic functions present in the polymer backbone. The lower thermal stability, determined by TGA, was observed for the polyurethane with an initial degradation temperature (temperature corresponding to $5 \mathrm{wt} \%$ loss: $T_{5 \%}$ ) of $307{ }^{\circ} \mathrm{C}$. The polycarbonate also showed a poor thermal stability $\left(T_{5 \%}=321^{\circ} \mathrm{C}\right)$. As expected, the polyamide, polyester, and polyether presented higher thermal stability with initial degradation temperatures of 343,386 , and $409^{\circ} \mathrm{C}$, respectively (Table 2 ).

Table 2. Thermal and thermomechanical characteristics of the polymers

\begin{tabular}{|c|c|c|c|c|c|}
\hline Monomer & Polymer & $\left.T_{c}\left[{ }^{\circ} \mathrm{C}\right] \mathrm{a}\right)$ & $\left.T_{\mathrm{m}}\left[{ }^{\circ} \mathrm{C}\right] \mathrm{a}\right)$ & $\left.\Delta H_{\mathrm{m}}\left[\mathrm{J} \mathrm{g}^{-1}\right] \mathrm{a}\right)$ & $\left.T_{5 \%}\left[{ }^{\circ} \mathrm{C}\right] \mathrm{b}\right)$ \\
\hline 1 & Polyurethane & 21 & 48 & 38 & 307 \\
\hline 2 & Polyester & 43 & 53 & 89 & 386 \\
\hline $1+2$ & Poly(ester-urethane) & 35 & 55 & 55 & 325 \\
\hline 3 & Polycarbonate & 36 & $36-49$ & $13-39$ & 321 \\
\hline 4 & Polyether & 50 & 60 & 99 & 409 \\
\hline 5 & Polyamide & 45 & 78 & 11 & 343 \\
\hline
\end{tabular}

Determined by: ${ }^{\text {a)} D S C ; ~}{ }^{\text {b)TGA. }}$

Regarding the thermomechanical properties evaluated by DSC analysis (Figure 3 ), the polyurethane exhibited a glass transition at $-25^{\circ} \mathrm{C}$. This low value was attributed to the purely aliphatic nature of the polymer. A melting point was noticed with a corresponding temperature of $48^{\circ} \mathrm{C}$. The melting enthalpy was quite low $\left(32 \mathrm{~J} \mathrm{~g}^{-1}\right)$ due to the remaining double bonds in the polymer structure, which restricts the chain packing and thus the 
crystallinity. Interestingly, the polyester showed higher melting temperature $\left(53^{\circ} \mathrm{C}\right)$ and corresponding enthalpy (89 $\mathrm{J} \mathrm{g}^{-1}$ ) in comparison to the polyurethane. The copolymer from (1) and (2) showed intermediate thermomechanical properties in comparison to the polyester and the polyurethane, respectively (Figure S13, Supporting Information). In the case of the polycarbonate, a complex melting pattern was observed with two melting peaks ( 36 and $49^{\circ} \mathrm{C}$, respectively) on heating the sample, most probably ascribed to polymorphism or to melting-recrystallization processes. The DSC curve of the polyether showed a melting temperature of $60^{\circ} \mathrm{C}$ with the higher melting enthalpy of $99 \mathrm{~J} \mathrm{~g}^{-1}$. The high crystalline ability of the polyether is given by the conformational flexibility of the ether linkage, which promotes chain packing. As expected, of all the investigated polymers, the polyamide showed the highest melting temperature $\left(78^{\circ} \mathrm{C}\right.$ ) due to the high cohesion (and thus to the high stability of the crystals) that amide functions confer to the polymeric material.

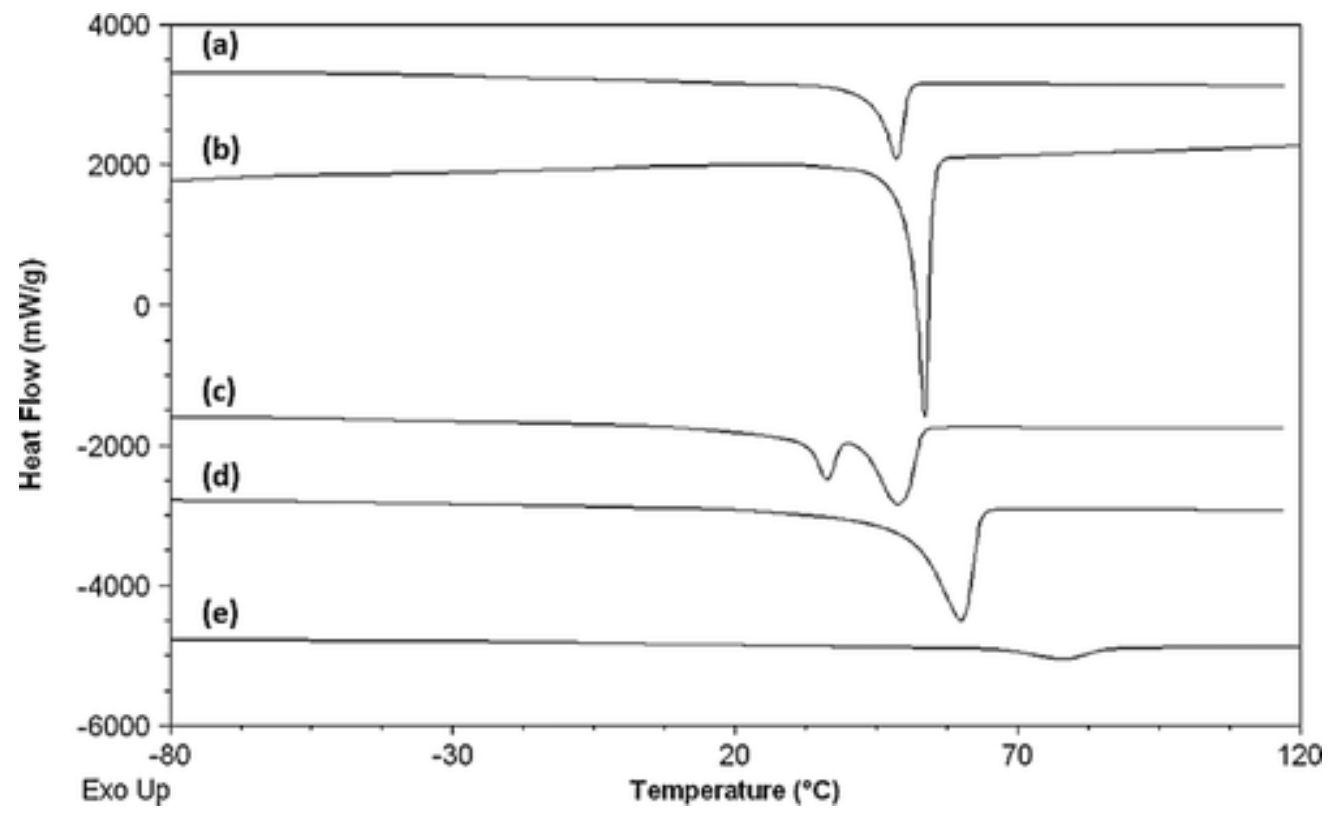

Figure 3 DSC 2nd heating curves of a) polyurethane, b) polyester, c) polycarbonate, d) polyether, and e) polyamide.

\section{Conclusion}

We have demonstrated that ADMET polymerization of a $\alpha, \omega$-diene urethane monomer could be readily achieved in bulk and in Polarclean. This methodology thus offers new reaction conditions for polyurethane synthesis in comparison to the classical route (polyaddition of polyols and polyisocyanates) or to transurethanization pathway. Moreover, the use of Polarclean constitutes a greener alternative to common high boiling solvents employed in ADMET polymerizations. Other bio-based $\alpha, \omega$-diene monomers bearing various organic functions can also be polymerized by ADMET, which resulted in good efficiency of Polarclean as a polymerization solvent when carbonate and ester monomers were used. An overview of the thermomechanical properties of these polymers showed significant variations in the melting temperature and melting enthalpy values depending on the organic function present in the polymer backbone. 


\section{Acknowledgements}

The authors thank Michèle Schappacher and Sylvain Mirieu for active participation to this work. This study was financially supported by the University of Bordeaux-1, ANR, IPB, CNRS, Aquitaine Council, ITERG, ONIDOL, and ADEME agency.

\section{References}

- 1 PlasticsEurope, 2010, http://www.plasticseurope.org, accessed June, 2013.

- 2 M. Desroches, M. Escouvois, R. Auvergne, S. Caillol, B. Boutevin, Polym. Rev. 2012, 52, 38.

- 3 G. Lligadas, J. C. Ronda, M. Galiá, V. Cádiz, Biomacromolecules 2010, 11, 2825.

- 4 L. Maisonneuve, T. Lebarbe, E. Grau, H. Cramail, Polym. Chem. 2013, 4( 22), 5472.

- 5 D. V. Palaskar, A. L. Boyer, E. Cloutet, C. Alfos, H. Cramail, Biomacromolecules 2010, 11, 1202.

- 6 A. Boyer, E. Cloutet, T. Tassaing, B. Gadenne, C. Alfos, H. Cramail, Green Chem. 2010, 12, 2205

- 7 A. S. More, B. Gadenne, C. Alfos, H. Cramail, Polym. Chem. 2012, 3, 1594.

- 8 G. C. Vougioukalakis, R. H. Grubbs, Chem. Rev. 2009, 110, 1746.

- 9 P. Atallah, K. B. Wagener, M. D. Schulz, Macromolecules 2013, 46, 4735.

- 10 H. Mutlu, L. M. de Espinosa, M. A. R. Meier, Chem. Soc. Rev. 2011, 40, 1404.

- 11 A. Rybak, M. A. R. Meier, ChemSusChem 2008, 1, 542.

- $\quad 12$ S. Warwel, F. Brüse, C. Demes, M. Kunz, M. R. G. Klaas, Chemosphere 2001, 43, 39.

- 13 M. A. R. Meier, Macromol. Chem. Phys. 2009, 210, 1073.

- 14 H. Mutlu, M. A. R. Meier, Macromol. Chem. Phys. 2009, 210, 1019.

- 15 D. S. Ogunniyi, Bioresource Technol. 2006, 97, 1086.

- 16 Rhodiasolv Web page, http://www.rhodia.com/fr/markets_and_products/brands/Novecare_Rhodiasolv_polarclean.tcm, accessed June, 2013.

- 17 S. H. Hong, D. P. Sanders, C. W. Lee, R. H. Grubbs, J. Am. Chem. Soc. 2005, 127, 17160.

- 18 P. A. Fokou, M. A. R. Meier, Macromol. Rapid Commun. 2010, 31, 368.

- 19 H. Mutlu, J. Ruiz, S. C. Solleder, M. A. R. Meier, Green Chem. 2012, 14, 1728.

- 20 O. Türünç, L. Montero de Espinosa, M. A. R. Meier, Macromol. Rapid Commun. 2011, 32, 1357.

- $\quad$ 21W. Lin, X. Zhang, Z. He, Y. Jin, L. Gong, A. Mi, Synth. Commun. 2002, 32, 3279. 


\section{Bio- based aliphatic polyurethanes through ADMET polymerization in bulk and green solvent.}

I nomas Leoarbe, ${ }^{a, b, d}$ Arvind Sudhakar More, ${ }^{a, b}$ Prakash Sudhir Sane, ${ }^{a, b}$ Etienne Grau, ${ }^{a, b}$ Carine Alfos, ${ }^{c}$ and Henri Cramail ${ }^{a, b}, *$

\section{Experimental Section}

\section{Materials and Instrumentation}

10-undecenoic acid (98\%) was supplied by TCI, Europe. 1,5,7-triazabicyclo[4.4.0]dec-5ene (TBD, 98\%), triethylamine (99\%), ethyl chloroformate (97\%), sodium azide (99.99\%), calcium hydride (95\%), Grubbs $1^{\text {st }}$ generation catalyst $(\mathrm{C} 1)$, Grubbs $2^{\text {nd }}$ generation catalyst (C2), Hoveyda-Grubbs $1^{\text {st }}$ generation catalyst (C3) and Hoveyda-Grubbs $2^{\text {nd }}$ generation catalyst (C4), dimethyl carbonate (99\%), 4-toluenesulfonyl chloride (>99\%), 11-bromo-1undecene (95\%), zinc dust (98\%) and 10-undecenoyl chloride ( $>97 \%)$ were obtained from Sigma-Aldrich. 10-undecenol (99\%) 1,4-benzoquinone (98\%) and dibutyltin dilaurate (DBTDL, 95\%) were purchased from Alfa Aesar. Methyl-5-(dimethylamino)-2-methyl-5oxopentanoate (polarclean ${ }^{\circledR}$ ) was kindly provided by Rhodia-Solvay. Polarclean was dried over $\mathrm{CaH}_{2}$ and cryodistilled prior to use.

All NMR experiments were performed at $298 \mathrm{~K}$ on a Bruker Avance I NMR spectrometer operating at $400 \mathrm{MHz}$ and equipped with a Bruker multinuclear z-gradient direct probe head capable of producing gradients in the $\mathrm{z}$ direction with strength $53.5 \mathrm{G} \mathrm{cm}^{-1}$. Infrared spectra were obtained on a Bruker-Tensor 27 spectrometer using the attenuated total reflection (ATR) mode. The spectra were acquired using 16 scans at a resolution of 4 wavenumbers. Size exclusion chromatography (SEC) analyses were performed in THF $\left(40^{\circ} \mathrm{C}\right)$ on a PL-GPC 50 
plus Integrated GPC from Polymer laboratories-Varian with a series of four columns from TOSOH (TSKgel TOSOH: HXL-L (guard column 6,0mm ID x 4,0cm L); G4000HXL $(7,8 \mathrm{~mm}$ ID x 30,0cm L) ;G3000HXL (7,8mm ID x 30,0cm L) and G2000HXL (7,8mm ID x $30,0 \mathrm{~cm} \mathrm{~L})$ ). The elution of the filtered samples was monitored using simultaneous refractive index and UV detection. The elution times were converted to molar mass using a calibration curve based on low dispersity $\left(\mathrm{M}_{\mathrm{w}} / \mathrm{M}_{\mathrm{n}}\right)$ polystyrene (PS) standards. The gas chromatography analyses (GC) were performed using a Shimadzu GC equipped with: Flame ionization detectors (FID, $380{ }^{\circ} \mathrm{C}$ ) and Zebron ZB-5HT (5\% phenyl - 95\% dimethylpolysiloxane) $15 \mathrm{~m}$ x $0.25 \mathrm{~mm}$ ID, $0.1 \mu \mathrm{m}$ thickness capillary column. The carrier gas was hydrogen. The column temperature was initially set at $60{ }^{\circ} \mathrm{C}$ (volume injected: $1 \mu \mathrm{l}$ ), then increased to $370{ }^{\circ} \mathrm{C}$ at a rate of $10{ }^{\circ} \mathrm{C} \cdot \mathrm{min}^{-1}$ and held isothermally for $10 \mathrm{~min}$. Differential scanning calorimetry (DSC) thermograms were measured using a DSC Q100 apparatus from TA instruments. Polymer samples were first heated from -100 to $120^{\circ} \mathrm{C}$ and then the glass transition temperatures and melting points were calculated from a second heating run. All runs were performed at a rate of $10{ }^{\circ} \mathrm{C} \min ^{-1}$. Thermogravimetric analyses (TGA) were performed on TGA-Q50 system from TA instruments at a heating rate of $10{ }^{\circ} \mathrm{C} \cdot \mathrm{min}^{-1}$ under nitrogen atmosphere.

\section{Synthesis of monomers}

10-undecenoyl azide To a suspension of 10-undecenoic acid (8.9 g, $48.3 \mathrm{mmol})$ in tetrahydrofuran:water $(50: 15 \mathrm{~mL})$ was added triethylamine $(9.77 \mathrm{~g}, 96.6 \mathrm{mmol})$. The clear solution obtained was then cooled to $0{ }^{\circ} \mathrm{C}$ and then ethyl chloroformate $(10.48 \mathrm{~g}, 96.6 \mathrm{mmol})$ was added drop-wise over a period of $10 \mathrm{~min}$. The reaction mixture was stirred for $2 \mathrm{~h}$ and then $\mathrm{NaN}_{3}(15.69 \mathrm{~g}, 241.5 \mathrm{mmol})$ in water $(10 \mathrm{~mL})$ was added drop-wise for $10 \mathrm{~min}$ and the stirring continued at $0{ }^{\circ} \mathrm{C}$ for $4 \mathrm{~h}$. Icecold-water $(20 \mathrm{~mL})$ was added to the crude product which was then extracted with DCM $(2 \times 75 \mathrm{~mL})$. The DCM solution was washed with water (3 x $40 \mathrm{~mL}$ ), dried over sodium sulphate and filtered. The solvent was evaporated under reduced pressure at room temperature to obtain 10-undecenoyl azide as viscous oil. Yield: 
$82 \%$. Organic acyl azides may be hazardous to manipulate due to their explosive tendency. Nevertheless, we voluntary employed 10-undecenoic acid as a precursor to the acyl azide compound due to its long methylene chain which affords a sufficient ratio value of oxygen and carbon atoms numbers $\left(\mathrm{N}_{\mathrm{C}}+\mathrm{N}_{\mathrm{O}}\right)$ to nitrogen atoms numbers $\left(\mathrm{N}_{\mathrm{N}}\right)$. Indeed, for organic azides to be safely manipulated, $\left(\left(\mathrm{N}_{\mathrm{C}}+\mathrm{N}_{\mathrm{O}}\right) / \mathrm{N}_{\mathrm{N}}\right)$ should be at least 3 . In our case the ratio value is 4 . The 10-undecenoyl azide can thus be manipulated if sufficient care is taken.

${ }^{1} \mathrm{H}$ NMR $\left(\mathrm{CDCl}_{3}, \delta / \mathrm{ppm}\right):$ 5.82-5.70 (m, 1H, $\left.-\mathrm{CH}=\mathrm{CH}_{2}\right), 4.94-4.84\left(\mathrm{~m}, 2 \mathrm{H}, \mathrm{CH}_{2}=\mathrm{CH}-\right), 3.28(\mathrm{t}$, $\left.2 \mathrm{H},-\mathrm{CH}_{2}-\mathrm{NCO}\right), 2.32\left(\mathrm{t}, 2 \mathrm{H},-\mathrm{CH}_{2}-\mathrm{CON}_{3}\right), 2.04\left(\mathrm{q}, 2 \mathrm{H},-\mathrm{CH}_{2}-\mathrm{CH}=\mathrm{CH}_{2}\right) 1.62\left(\mathrm{~m}, 2 \mathrm{H},-\mathrm{CH}_{2}-\right.$ $\left.\mathrm{CH}_{2}-\mathrm{CON}_{3}\right), 1.20-1.45\left(\mathrm{~m}, 8 \mathrm{H},-\mathrm{CH}_{2^{-}}\right)$.

Bis-unsaturated urethane (1) To a solution of undecylenic acyl azide (4.18 g, $20 \mathrm{mmol})$ in anhydrous THF, under nitrogen stream was slowly added 10-undecen-1-ol (3) (3.41 g, 20 mmol) and a drop of DBTDL. The reaction mixture was heated at $50{ }^{\circ} \mathrm{C}$ for overnight. After completion of reaction, the THF was evaporated under reduced pressure and to the crude product was added petroleum ether. The solid separated was filtered off and the filtrate concentrated on rotavapor to give bis-unsaturated urethane compound (2). The further purification was carried out using flash column chromatography (Pentane/ethyl acetate: 80/20). Yield: $63 \%$.

${ }^{1} \mathrm{H}$ NMR $\left(\mathrm{CDCl}_{3}, \delta / \mathrm{ppm}\right): 5.82-5.70\left(\mathrm{~m}, 2 \mathrm{H},-\mathrm{CH}=\mathrm{CH}_{2}\right), 4.94-4.84(\mathrm{~m}, 4 \mathrm{H}, \mathrm{CH}=\mathrm{CH}-), 4.62$ (m, 1H, -NH-), 4.03 (t, 2H, - $\left.\mathrm{CH}_{2}-\mathrm{O}-\mathrm{CO}-\mathrm{NH}-\right), 3.14$ (q, 2H, - $\left.\mathrm{CH}_{2}-\mathrm{NH}-\mathrm{CO}-\mathrm{O}-\right), 2.04$ (q, 4H, $\left.\mathrm{CH}_{2}-\mathrm{CH}=\mathrm{CH}_{2}\right), 1.59$ (m, 2H, $\left.-\mathrm{CH}_{2}-\mathrm{CH}_{2}-\mathrm{O}-\mathrm{CO}-\mathrm{NH}-\right), 1.47$ (m, 2H, - $\left.\mathrm{CH}_{2}-\mathrm{CH}_{2}-\mathrm{NH}-\mathrm{CO}-\mathrm{O}-\right)$, 1.20-1.40 (m, 22H, $\left.-\mathrm{CH}_{2^{-}}\right)$.

${ }^{13} \mathrm{C}$ NMR $\left(\mathrm{CDCl}_{3}, \delta / \mathrm{ppm}\right): 156.80(-\mathrm{NH}-\mathrm{CO}-\mathrm{O}-), 139.20\left(-\mathrm{CH}=\mathrm{CH}_{2}\right), 114.12\left(\mathrm{CH}_{2}=\mathrm{CH}-\right)$, $64.89\left(-\mathrm{CH}_{2}-\mathrm{O}-\mathrm{CO}-\mathrm{NH}-\right), 40.99\left(-\mathrm{CH}_{2}-\mathrm{NH}-\mathrm{CO}-\mathrm{O}-\right), 33.73\left(-\mathrm{CH}_{2}-\mathrm{CH}=\mathrm{CH}_{2}\right), 25-31\left(-\mathrm{CH}_{2}-\right)$.

Bis-unsaturated ester (2) Methyl 10-undecenoate (15.00 g, 75.6mmol), 10-undecenol (12.87 g, 75.6mmol) and TBD (1: 1: 0.05) were stirred under nitrogen flow at $120{ }^{\circ} \mathrm{C}(4 \mathrm{~h})$, at $160{ }^{\circ} \mathrm{C}$ $(2 \mathrm{~h})$ then under vacuum at $160{ }^{\circ} \mathrm{C}(1 \mathrm{~h})$. After completion of the reaction, the product was 
purified using flash column chromatography (Heptane/diethyl ether: 80/20). Yield: 81\%. Purity by GC: $99 \%$.

${ }^{1} \mathrm{H}$ NMR $\left(\mathrm{CDCl}_{3}, \delta / \mathrm{ppm}\right):$ 5.82-5.70 (m, 2H, $\left.-\mathrm{CH}=\mathrm{CH}_{2}\right), 4.94-4.84\left(\mathrm{~m}, 4 \mathrm{H}, \mathrm{CH}_{2}=\mathrm{CH}-\right), 4.05(\mathrm{t}$, $\left.2 \mathrm{H},-\mathrm{CH}_{2}-\mathrm{O}-\mathrm{CO}-\right), 2.28$ (t, 2H, $\left.-\mathrm{CH}_{2}-\mathrm{CO}-\mathrm{O}-\right), 2.04$ (q, 4H, $-\mathrm{CH}_{2}-\mathrm{CH}=\mathrm{CH}_{2}$ ), 1.59 (m, 2H, $\left.\mathrm{CH}_{2}-\mathrm{CH}_{2}-\mathrm{O}-\mathrm{CO}-\right), 1.20-1.45$ (m, 24H, $\left.-\mathrm{CH}_{2}{ }^{-}\right)$.

Bis-unsaturated carbonate (3) 10-undecenol (20.8 g, 122.1mmol), dimethyl carbonate (5.50 $\mathrm{g}, 61.1 \mathrm{mmol})$ and $\operatorname{TBD}(1: 0.5: 0.05)$ were stirred under nitrogen atmosphere at $80{ }^{\circ} \mathrm{C}(2 \mathrm{~h})$, and then under nitrogen flow at the same temperature $(4 \mathrm{~h})$ then under vacuum at $80^{\circ} \mathrm{C}(1 \mathrm{~h})$. After completion of the reaction, the product was purified using flash column chromatography (Heptane/ethyl acetate: 90/10). Yield: 75\%. Purity by GC: $99 \%$.

${ }^{1} \mathrm{H}$ NMR $\left(\mathrm{CDCl}_{3}, \delta / \mathrm{ppm}\right):$ 5.82-5.70 (m, 2H, $\left.-\mathrm{CH}=\mathrm{CH}_{2}\right), 4.94-4.84\left(\mathrm{~m}, 4 \mathrm{H}, \mathrm{CH}_{2}=\mathrm{CH}-\right), 4.11(\mathrm{t}$, 4H, - $\left.\mathrm{CH}_{2}-\mathrm{O}-\mathrm{CO}-\mathrm{O}\right), 2.04$ (q, 4H, $-\mathrm{CH}_{2}-\mathrm{CH}=\mathrm{CH}_{2}$ ), 1.66 (m, 4H, - $\left.\mathrm{CH}_{2}-\mathrm{CH}_{2}-\mathrm{O}-\mathrm{CO}-\mathrm{O}\right), 1.20-$ $1.45\left(\mathrm{~m}, 24 \mathrm{H},-\mathrm{CH}_{2-}\right)$.

1-tosyl-10-undecene Into a two necked round bottom flask equipped with magnetic stirrer and additional funnel, 10-undecen-1-ol (10 g, $58.82 \mathrm{mmol})$ and triethylamine $(5.95 \mathrm{~g}, 58.82$ mmol) were dissolved in dichloromethane $(100 \mathrm{~mL})$. The solution was cooled at $0{ }^{\circ} \mathrm{C}$ in an ice bath. Solution of 4-toluenesulfonyl chloride (11.17 g, $58.82 \mathrm{mmol})$ in dichloromethane (25 $\mathrm{mL}$ ) was slowly added to the cooled solution through additional funnel. The reaction mixture was stirred at $0{ }^{\circ} \mathrm{C}$ for $2 \mathrm{~h}$ and at room temperature overnight. The reaction mixture was filtered and the organic layer was washed with $5 \% \mathrm{NaHCO}_{3}(3 \times 100 \mathrm{~mL})$ and water $(3 \times 100$ $\mathrm{mL}$ ). The organic layer was dried over anhydrous sodium sulphate, filtered and chloroform was evaporated under reduced pressure. The crude product was purified by silica gel column chromatography using a mixture of ethyl acetate: petroleum ether $(10: 90, \mathrm{v} / \mathrm{v})$ as eluent. The removal of the solvent yielded $18.70 \mathrm{~g}$ (98 \%) of 1-tosyl-10-undecene as a pale yellow liquid. 
${ }^{1} \mathrm{H}$ NMR $\left(\mathrm{CDCl}_{3}, \delta / \mathrm{ppm}\right): 7.74(\mathrm{~d}, 2 \mathrm{H}, \mathrm{Ar}-H), 7.25(\mathrm{~d}, 2 \mathrm{H}, \mathrm{Ar}-H), 5.82-5.70(\mathrm{~m}, 1 \mathrm{H},-$ $\left.\mathrm{CH}=\mathrm{CH}_{2}\right), 4.94-4.84\left(\mathrm{~m}, 2 \mathrm{H}, \mathrm{CH}_{2}=\mathrm{CH}-\right), 3.96\left(\mathrm{t}, 2 \mathrm{H},-\mathrm{OCH}_{2^{-}}\right), 2.37\left(\mathrm{~s}, 3 \mathrm{H},-\mathrm{CH}_{3}\right), 2.04(\mathrm{q}$, $\left.2 \mathrm{H},-\mathrm{CH}_{2}-\mathrm{CH}=\mathrm{CH}_{2}\right), 1.56\left(\mathrm{~m}, 2 \mathrm{H},-\mathrm{CH}_{2}-\mathrm{CH}_{2}-\mathrm{O}-\right), 1.20-1.45\left(\mathrm{~m}, 12 \mathrm{H},-\mathrm{CH}_{2}-\right)$.

Bis-unsaturated ether (4) Into a two necked round bottom flask equipped with magnetic stirrer, slurry of sodium hydride $(0.576 \mathrm{~g}, 23.52 \mathrm{mmol})$ in dimethylsulfoxide $(25 \mathrm{~mL})$ was formed. Solution of 10-Undecen-1-ol $(1.0 \mathrm{~g}, 5.88 \mathrm{mmol})$ in dimethylsulfoxide $(10 \mathrm{~mL})$ was slowly added. The reaction mixture was stirred at room temperature for 10 minutes. To this, 1-tosyl-10-Undecene $(1.81 \mathrm{~g}, 5.88 \mathrm{mmol})$ was added slowly. After 12h, dimethylsulfoxide was removed under reduced pressure and excess sodium hydride was deactivated by aqueous solution of ammonium chloride. Dichloromethane $(50 \mathrm{~mL})$ was added. The organic layer was washed with $5 \% \mathrm{NaHCO}_{3}(3 \times 100 \mathrm{~mL})$ and water $(3 \times 100 \mathrm{~mL})$. The organic layer was dried over anhydrous sodium sulphate, filtered and chloroform was evaporated under reduced pressure. The crude product was purified by silica gel column chromatography using a mixture of ethyl acetate: petroleum ether $(5: 95, \mathrm{v} / \mathrm{v})$ as eluent. Yield: $88 \%$. Purity by GC: $99 \%$.

${ }^{1} \mathrm{H}$ NMR ( $\left.\mathrm{CDCl}_{3}, \delta / \mathrm{ppm}\right):$ 5.82-5.70 (m, 2H, $\left.-\mathrm{CH}=\mathrm{CH}_{2}\right), 4.94-4.84\left(\mathrm{~m}, 4 \mathrm{H}, \mathrm{CH}_{2}=\mathrm{CH}-\right), 3.31$ (t, $\left.4 \mathrm{H},-\mathrm{O}-\mathrm{CH}_{2}-\right), 2.04\left(\mathrm{q}, 4 \mathrm{H},-\mathrm{CH}_{2}-\mathrm{CH}=\mathrm{CH}_{2}\right), 1.47\left(\mathrm{~m}, 4 \mathrm{H},-\mathrm{CH}_{2}-\mathrm{CH}_{2}-\mathrm{O}-\right), 1.20-1.45(\mathrm{~m}, 24 \mathrm{H}$, $-\mathrm{CH}_{2-}^{-}$.

1-azido-10-undecene To a $250 \mathrm{~mL}$, round-bottom flask equipped with a stirring bar, sodium azide $(9.56 \mathrm{~g}, 147 \mathrm{mmol})$ and $40 \mathrm{~mL}$ of dimethylformamide (DMF) were transferred. To the stirred solution, 1-bromo-10-undecene $(8.57 \mathrm{~g}, 37 \mathrm{mmol})$ was added dropwise, and the entire mixture was allowed to stir for $12 \mathrm{~h}$. The azide mixture was then transferred to a separating funnel and extracted with ether and water at a ratio 1:1. The ether layer was washed with water three times to remove DMF, dried over anhydrous sodium sulphate and concentrated under reduced pressure to end-up with 1-azido-10-undecene compound. Yield: $81 \%$. 
${ }^{1} \mathrm{H}$ NMR $\left(\mathrm{CDCl}_{3}, \delta / \mathrm{ppm}\right):$ 5.82-5.70 (m, $\left.1 \mathrm{H},-\mathrm{CH}=\mathrm{CH}_{2}\right), 4.94-4.84\left(\mathrm{~m}, 2 \mathrm{H}, \mathrm{CH}_{2}=\mathrm{CH}-\right), 3.25(\mathrm{t}$, $\left.2 \mathrm{H},-\mathrm{CH}_{2}-\mathrm{N}_{3}\right), 2.04\left(\mathrm{q}, 2 \mathrm{H},-\mathrm{CH}_{2}-\mathrm{CH}=\mathrm{CH}_{2}\right), 1.58\left(\mathrm{~m}, 2 \mathrm{H},-\mathrm{CH}_{2}-\mathrm{CH}_{2}-\mathrm{N}_{3}\right), 1.20-1.45(\mathrm{~m}, 12 \mathrm{H}$, $-\mathrm{CH}_{2-}^{-}$.

1-amino-10-undecene Reduction of azide to amine was performed by following reported procedures. $^{21}$ To a solution of azide $(6 \mathrm{~g}, 30.7 \mathrm{mmol})$ and ammonium chloride $(7.49 \mathrm{~g}$, $140 \mathrm{mmol})$ in ethyl alcohol and water (150: 50/v: v), zinc dust (3.9 g, 60mmol) was added, the mixture was stirred vigorously at refluxing for $1 \mathrm{~h}$. After the reaction is over, ethyl acetate and aqueous ammonia $(20 \mathrm{~mL})$ was added. The mixture was filtered, and the filtrate was washed with brine, dried over anhydrous sodium sulfate and concentrated under reduced pressure. Yield: $63 \%$.

${ }^{1} \mathrm{H} \mathrm{NMR}\left(\mathrm{CHCl}_{3}, \delta / \mathrm{ppm}\right):$ 5.82-5.70 (m, $\left.1 \mathrm{H},-\mathrm{CH}=\mathrm{CH}_{2}\right), 4.94-4.84\left(\mathrm{~m}, 2 \mathrm{H}, \mathrm{CH}_{2}=\mathrm{CH}-\right), 2.67$ (t, $\left.2 \mathrm{H},-\mathrm{CH}_{2}-\mathrm{NH}_{2}\right), 2.04\left(\mathrm{q}, 2 \mathrm{H},-\mathrm{CH}_{2}-\mathrm{CH}=\mathrm{CH}_{2}\right), 1.42\left(\mathrm{~m}, 2 \mathrm{H},-\mathrm{CH}_{2}-\mathrm{CH}_{2}-\mathrm{NH}_{2}\right), 1.20-1.45$ (m, $\left.12 \mathrm{H},-\mathrm{CH}_{2-}^{-}\right)$.

Bis-unsaturated amide (5) To a 500mL, round-bottom flask equipped with a stirring bar, a solution of triethylamine $(2.69 \mathrm{~g}, 26.6 \mathrm{mmol})$ and 1-amino-10-undecene (3 g, 17.75mmol) in THF was transferred. 10 -undecenoyl chloride $(3.60 \mathrm{~g}, 17.75 \mathrm{mmol})$ was added dropwise to the solution at $0^{\circ} \mathrm{C}$. After addition, the reaction mixture was stirred for $24 \mathrm{~h}$ at room temperature under nitrogen atmosphere. After completion of the reaction, the obtained suspension was filtered to remove triethylamine salt and THF was removed under reduced pressure. The product was purified by column chromatography using a mixture of cyclohexane: ethyl acetate (90:10 / v: v). The bis-unsaturated amide was obtained as a light yellow solid. Yield: $69 \%$.

${ }^{1} \mathrm{H}$ NMR $\left(\mathrm{CDCl}_{3}, \delta / \mathrm{ppm}\right)$ : 5.82-5.70 (m, 2H, $\left.-\mathrm{CH}=\mathrm{CH}_{2}\right), 4.94-4.84\left(\mathrm{~m}, 4 \mathrm{H}, \mathrm{CH}_{2}=\mathrm{CH}-\right), 3.24$ (t, 2H, - $\left.\mathrm{CH}_{2}-\mathrm{NH}-\mathrm{CO}-\right), 2.14$ (t, 2H, - $\left.\mathrm{CH}_{2}-\mathrm{CO}-\mathrm{NH}-\right), 2.04$ (q, 4H, $\left.-\mathrm{CH}_{2}-\mathrm{CH}=\mathrm{CH}_{2}\right), 1.62$ (m, 2H, $\left.\mathrm{CH}_{2}-\mathrm{CH}_{2}-\mathrm{NH}-\mathrm{CO}-\right), 1.20-1.45$ (m, 24H, $\left.-\mathrm{CH}_{2}-\right)$.

\section{Polymerization reactions}


Polymerizations in solution. Typical procedure for the solution polymerization in Polarclean was as follow. Monomers were dried under vacuum at $70^{\circ} \mathrm{C}$ overnight prior to use. In a round-bottom flask was transferred a solution of the monomer with $0.5 \mathrm{~mol} \%$ of metathesis catalyst (and $5 \mathrm{~mol} \%$ of 1,4 -benzoquinone in the case of ruthenium $2^{\text {nd }}$ generation catalysts) in polarclean. The reaction mixture was stirred at $80^{\circ} \mathrm{C}$ for $24 \mathrm{~h}$ under dynamic vacuum. After completion of the reaction, ethylvinyl ether was added and the mixture was stirred at room temperature for 30 minutes under nitrogen atmosphere to deactivate metathesis catalyst. Dynamic vacuum was then applied to remove excess ethylvinyl ether. The reaction mixture was then precipitated in methanol in order to remove all the polarclean solvent. Polymers were finally dried overnight at $70^{\circ} \mathrm{C}$ under dynamic vacuum.

Polymerizations in bulk. All monomers were dried under vacuum at $70^{\circ} \mathrm{C}$ overnight prior to reaction. In a round-bottom flask was transferred the monomer feed, with $0.5 \mathrm{~mol} \%$ of metathesis catalyst (and $5 \mathrm{~mol} \%$ of 1,4 -benzoquinone in the case of ruthenium $2^{\text {nd }}$ generation catalysts). The reaction mixture was stirred at $80^{\circ} \mathrm{C}$ for $24 \mathrm{~h}$ under dynamic vacuum. Tetrahydrofuran (THF) and ethylvinyl ether were then added and the mixture was stirred at room temperature for 30 minutes under nitrogen atmosphere. Dynamic vacuum was then applied. The reaction mixture was dissolved in dichloromethane and the polymer was precipitated in methanol and dried overnight at $70^{\circ} \mathrm{C}$ under vacuum.

All polymerizations in bulk and in solution led to a yield between 50 and $75 \%$. Only the polyesters synthesized in Polarclean from (2) by using $\mathbf{C 1}$ and $\mathbf{C 2}$ were obtained with a lower yield of around $20 \%$ and the polyether synthesized in Polarclean, which was obtained with a $38 \%$ yield. 
Figure S1-FTIR-ATR stacked spectra of 10-undecenoic acid, 10-undecenoyl azide and bisunsaturated urethane.

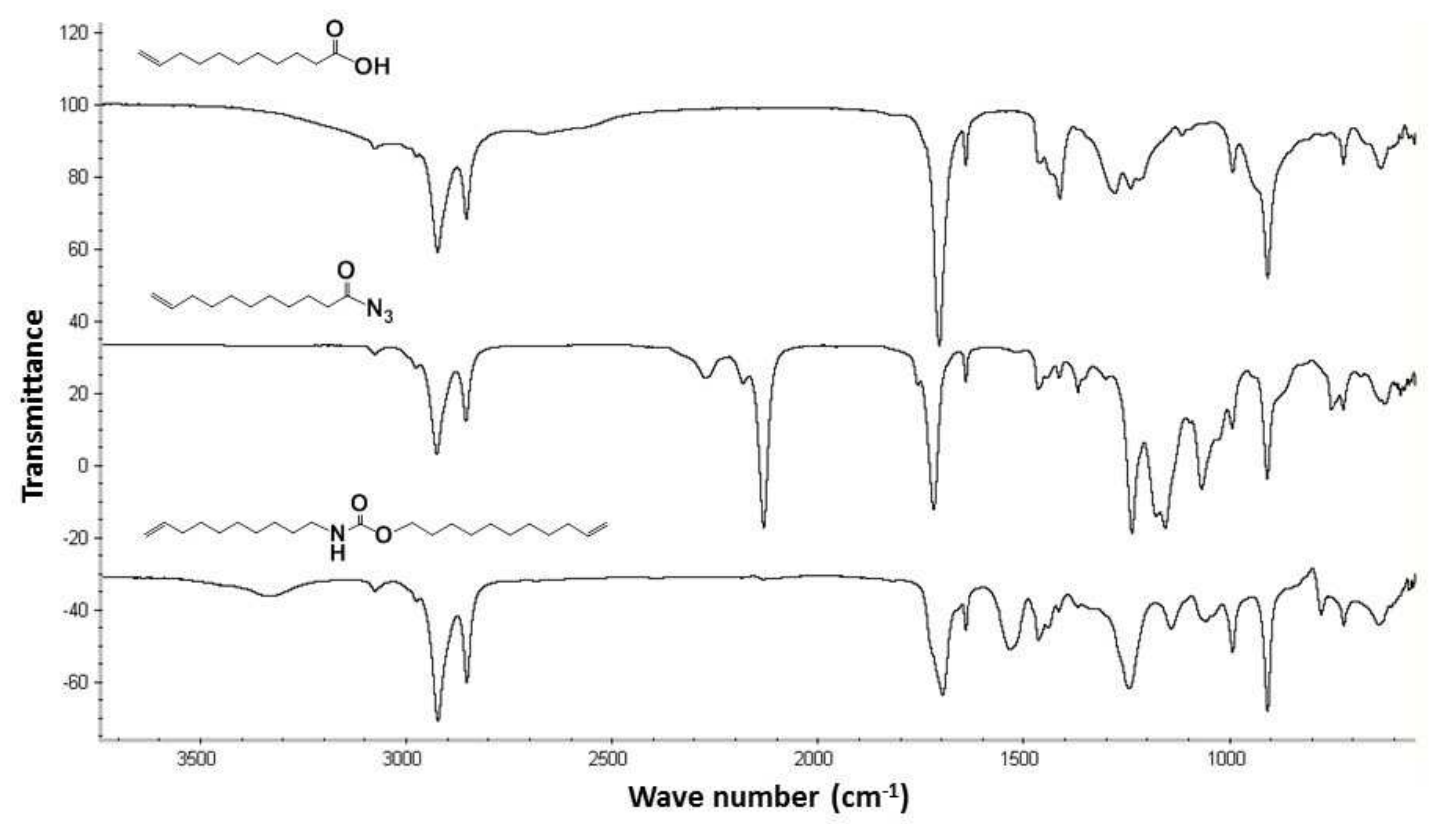

Figure S2- ${ }^{13} \mathrm{C}$-NMR spectrum of the bis-unsaturated urethane (1) in $\mathrm{CDCl}_{3}$.

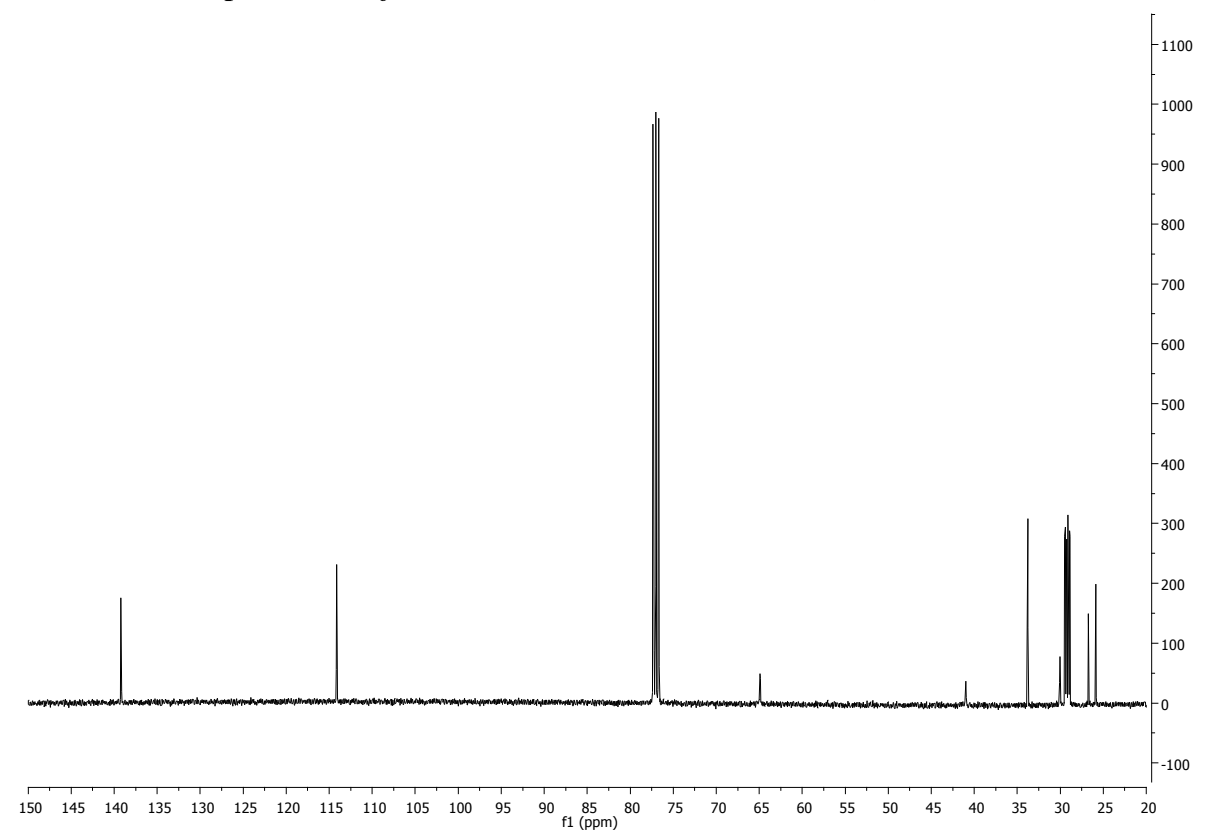


Figure S3- ${ }^{1} \mathrm{H}_{-}{ }^{13} \mathrm{C} H S Q C-N M R$ spectra of the bis-unsaturated urethane (1) in $\mathrm{CDCl}_{3}$.

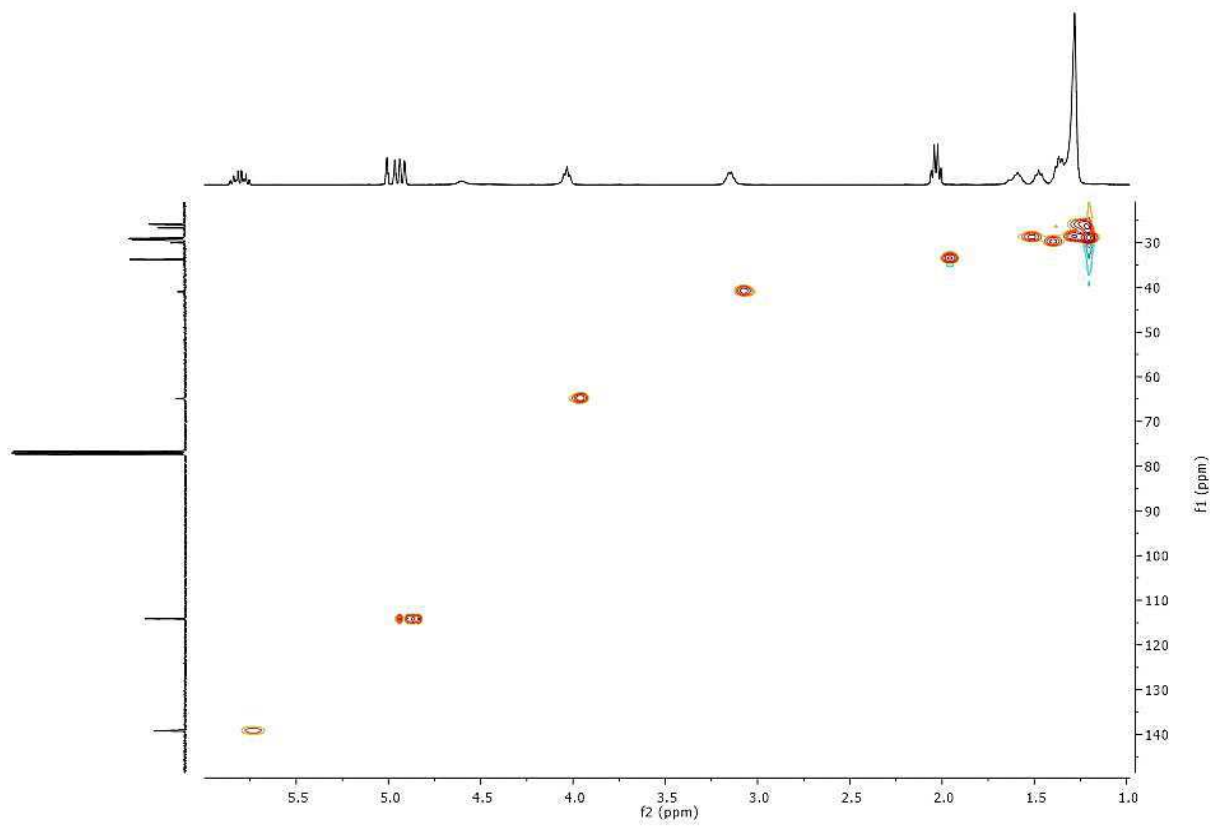

Figure S4- ${ }^{1} \mathrm{H}-{ }^{1} \mathrm{H}$ COSY-NMR spectra of the bis-unsaturated urethane (1) in $\mathrm{CDCl}_{3}$. 


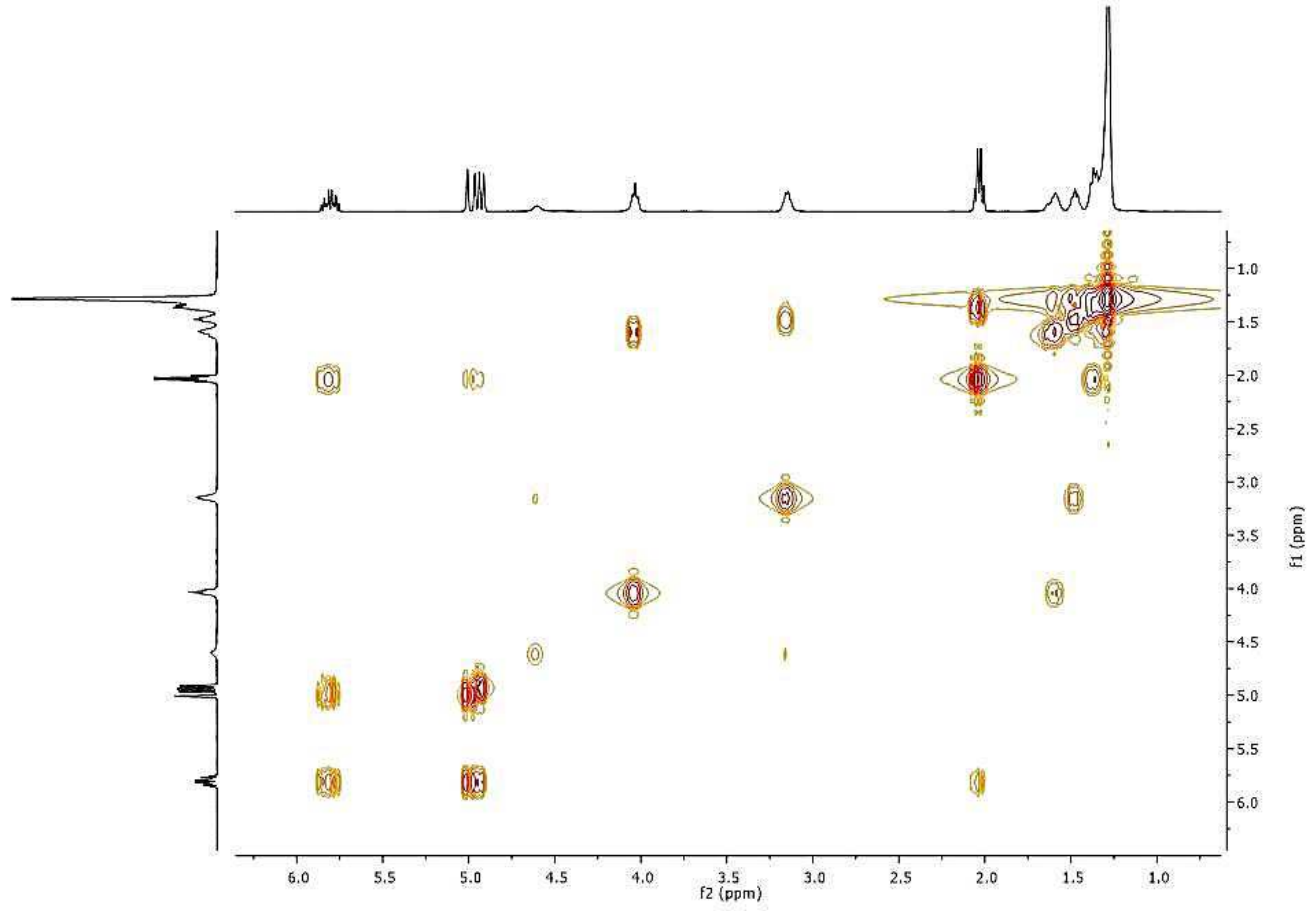

Figure $S 5-{ }^{1} \mathrm{H}$-NMR spectrum of the bis-unsaturated ester (2) in $\mathrm{CDCl}_{3}$.

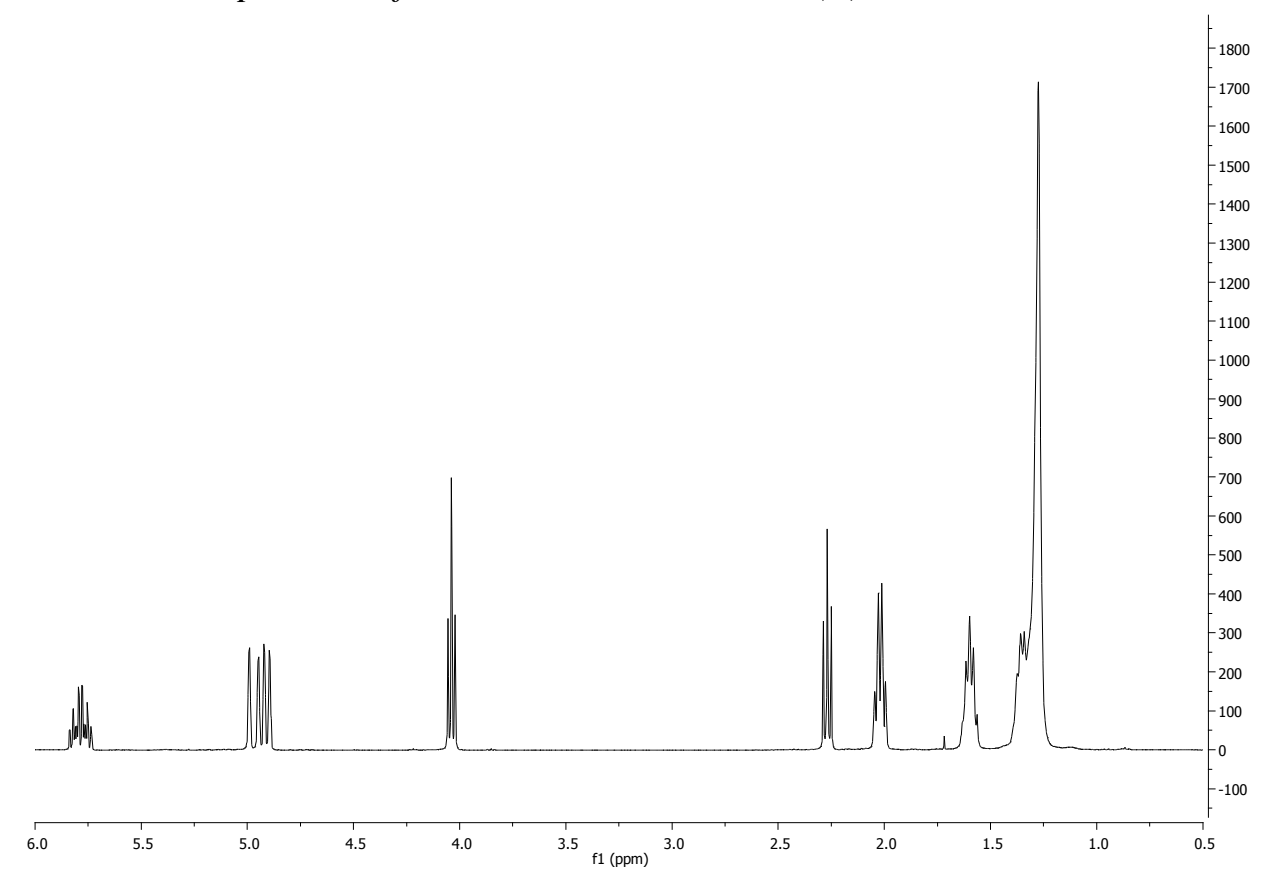

Figure S6-GC chromatogram of the bis-unsaturated ester (2). Peaks are assigned and integrations reported. 


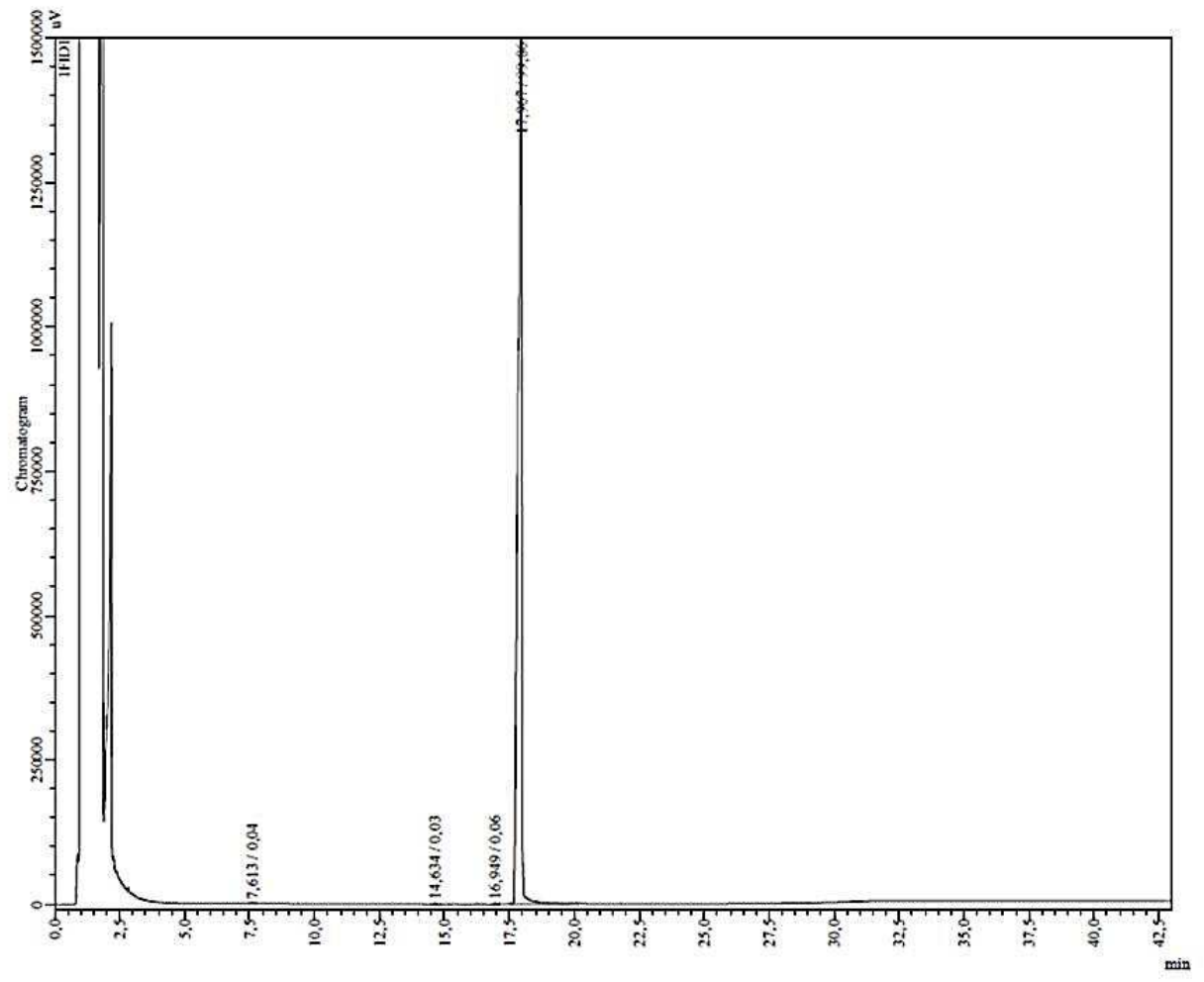

Figure S7- ${ }^{1} H$-NMR stacked spectra of the polyurethanes synthesized in bulk from (a) C1, (b) C2, (c) C3 and (d) C4. CDCl . 


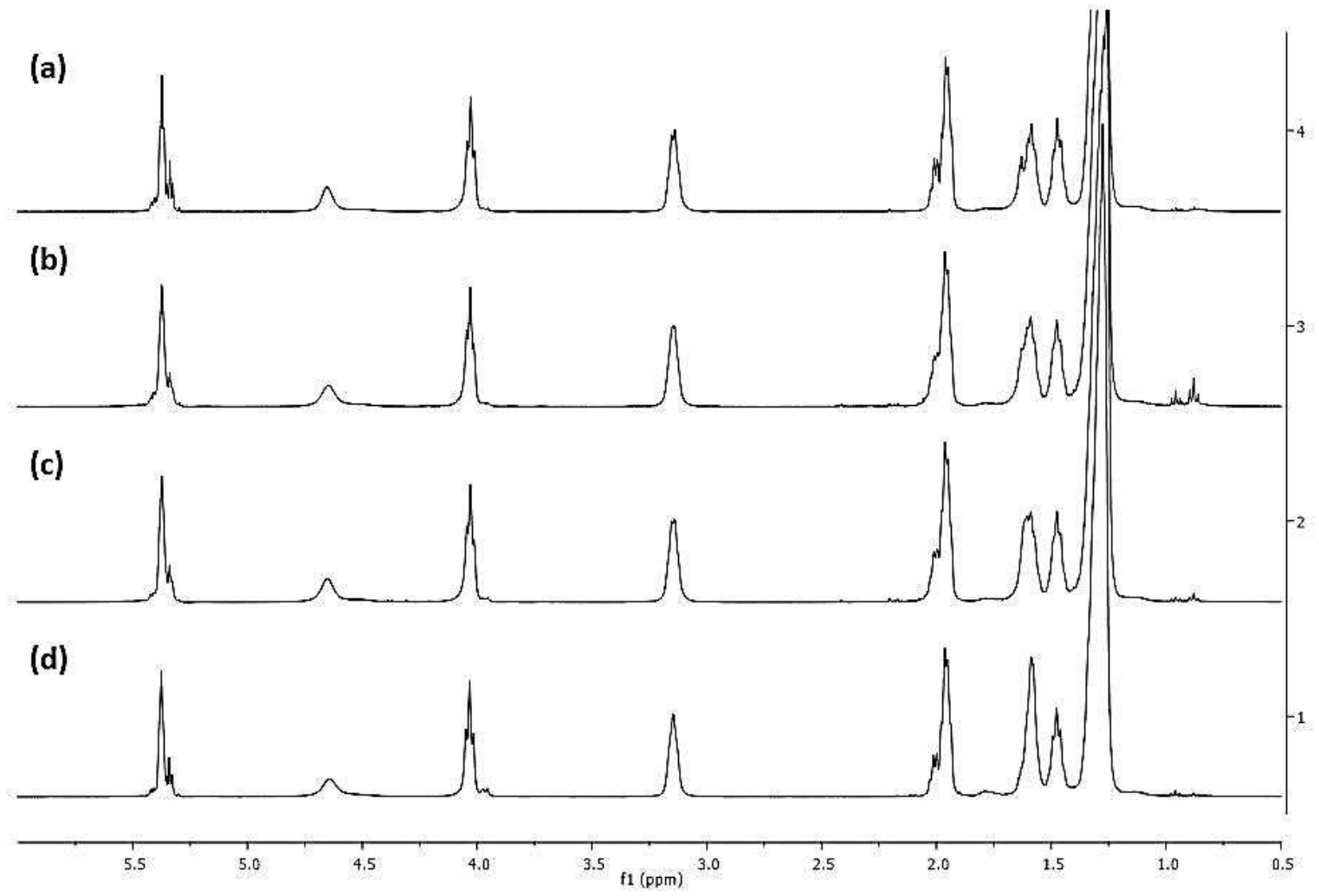

Figure $S 8-{ }^{1} \mathrm{H}$-NMR spectrum of the bis-unsaturated carbonate (3) in $\mathrm{CDCl}_{3}$.

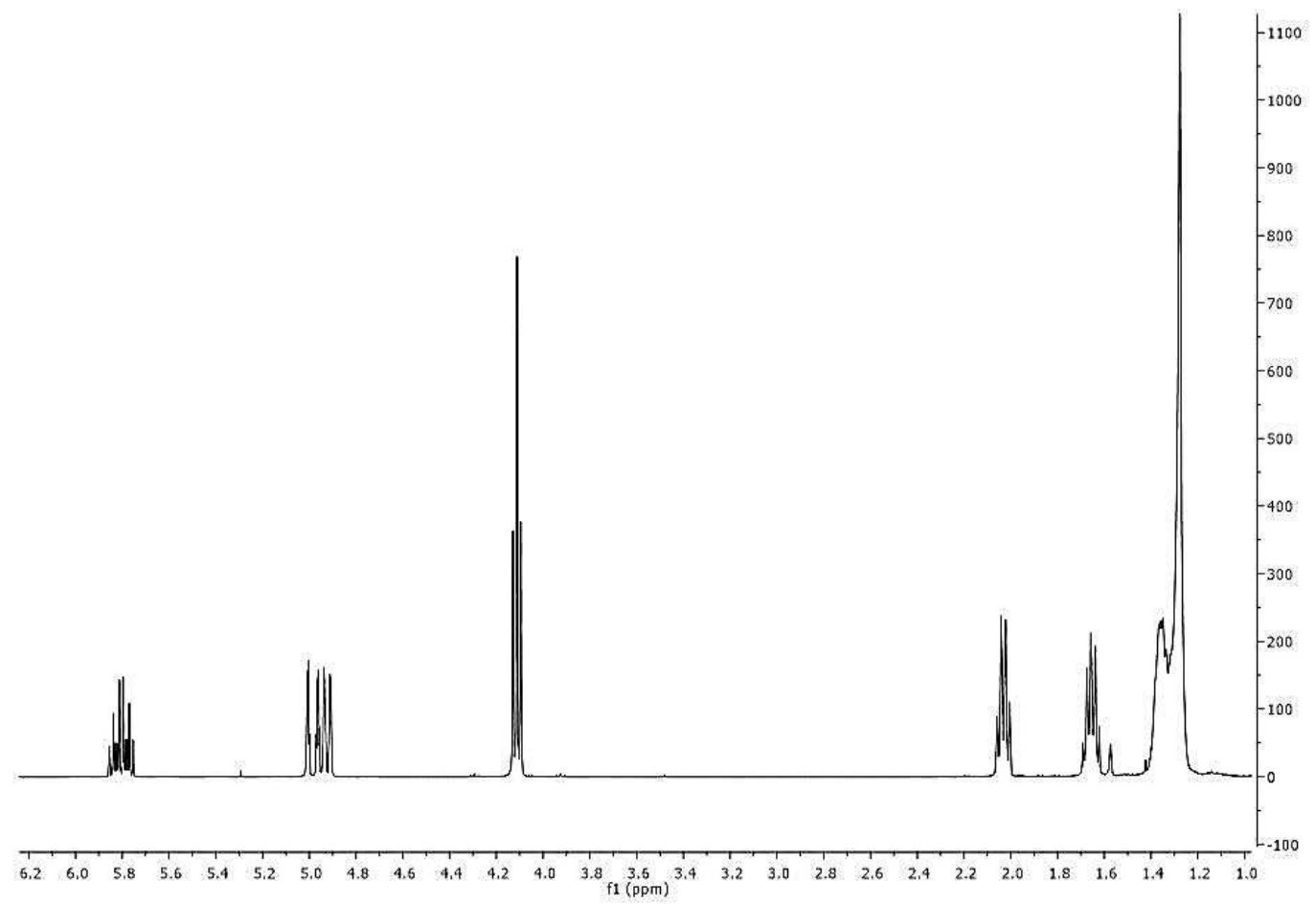

Figure S9-GC chromatogram of the bis-unsaturated carbonate (3). Peaks are assigned and integrations reported. 


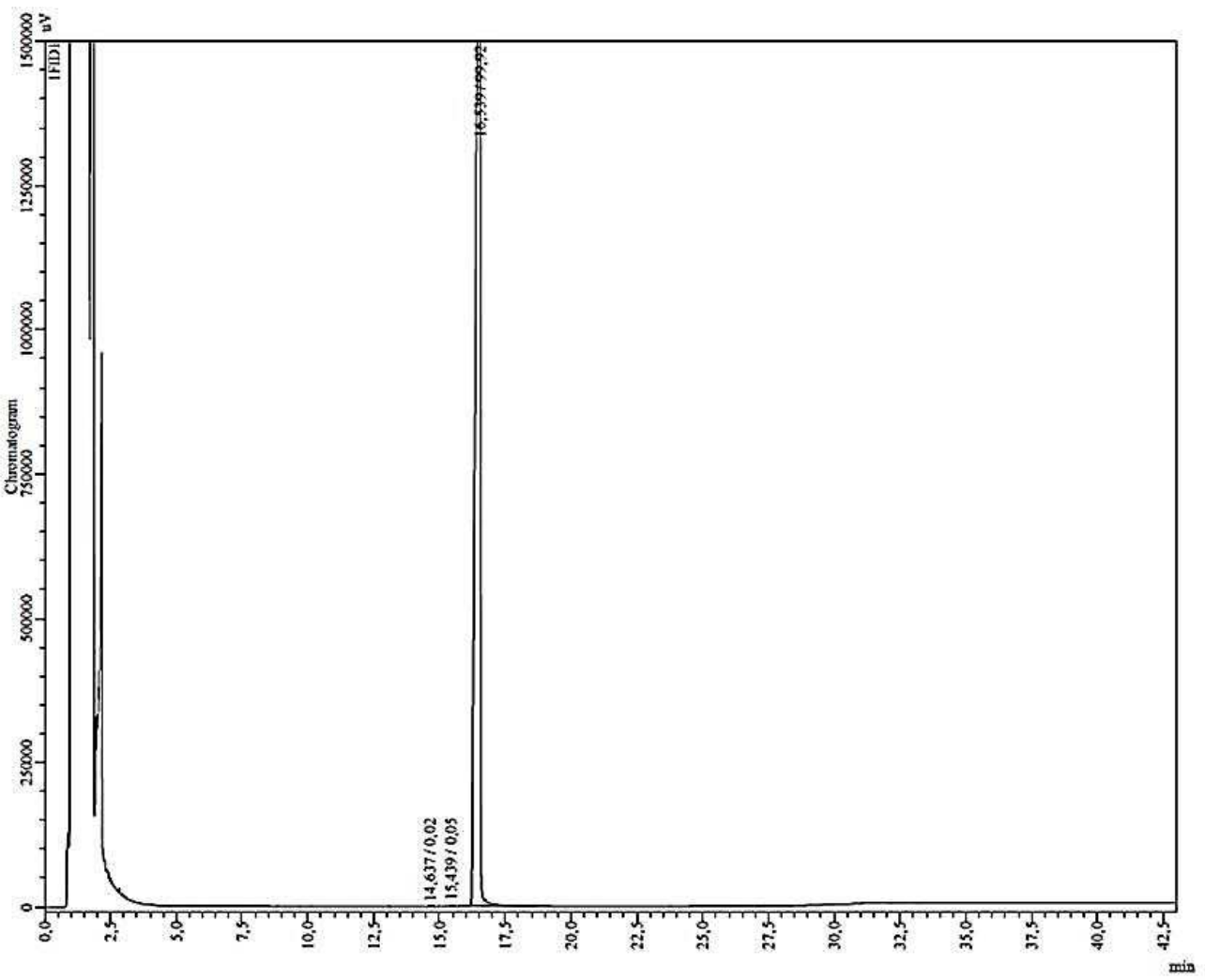

Figure S10- ${ }^{1} H$-NMR stacked spectra of 10-undecenoic acid, 1-tosyl-10-undecene and bisunsaturated ether (4) in $\mathrm{CDCl}_{3}$. 


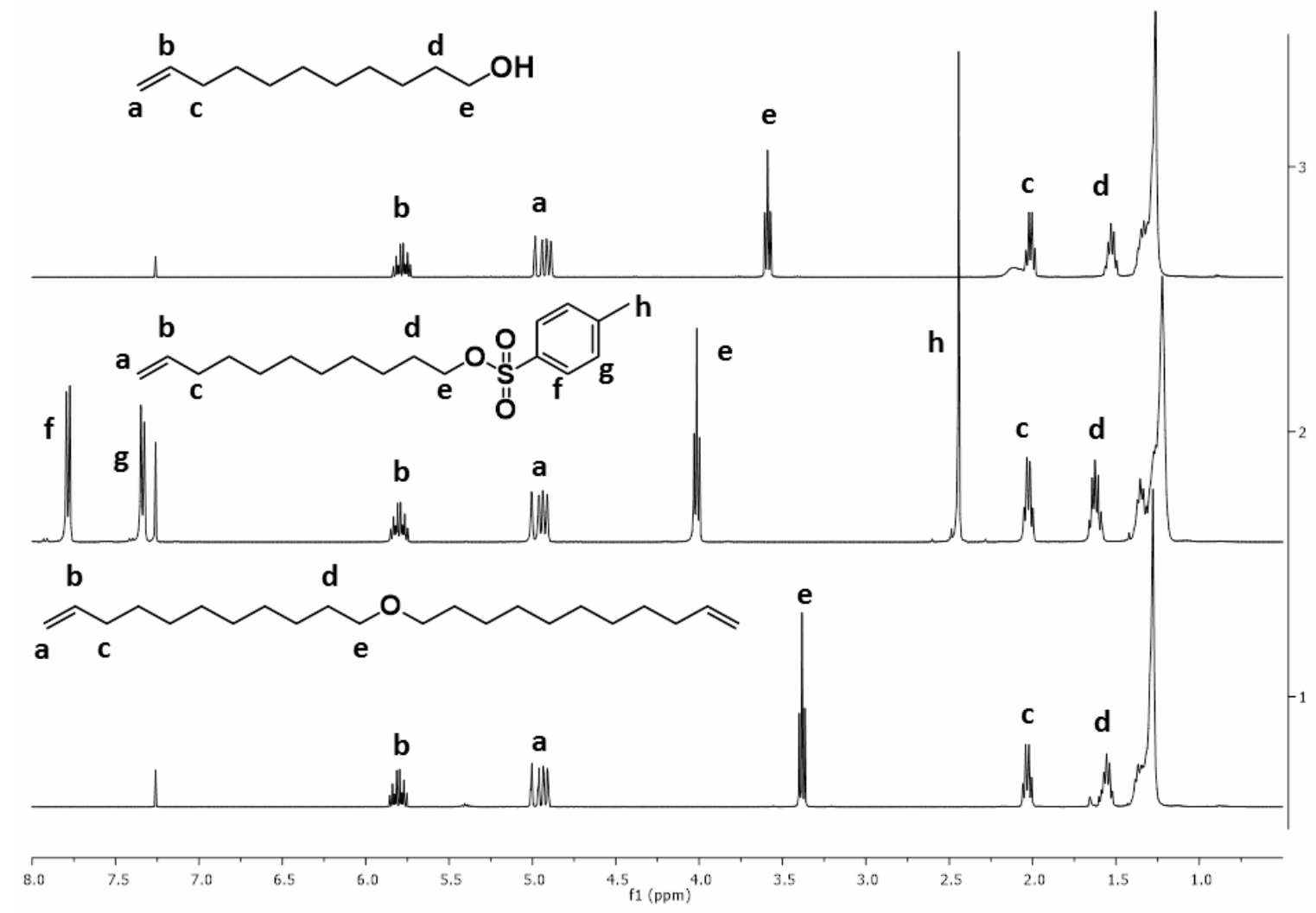

Figure S11-GC chromatogram of the bis-unsaturated ether (4). Peaks are assigned and integrations reported. 


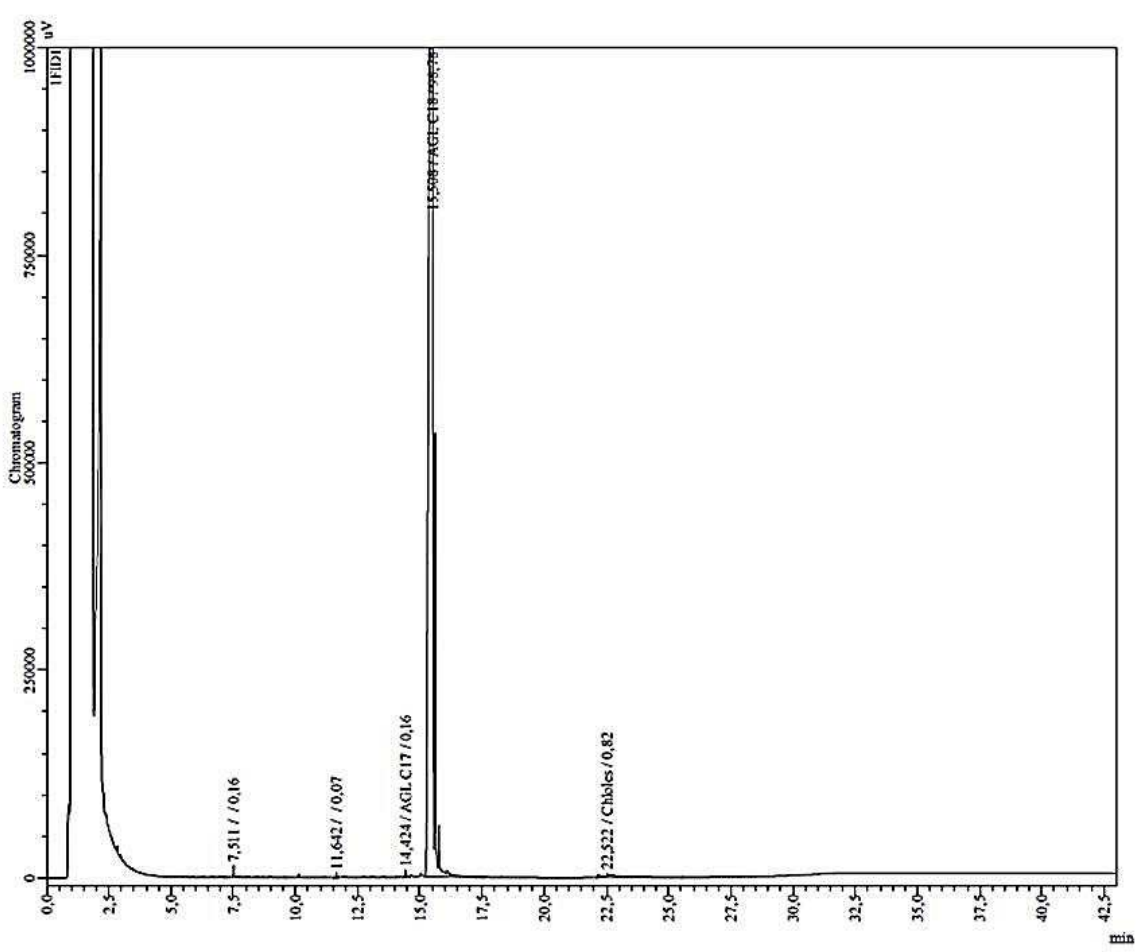

Figure S12- ${ }^{1}$ H-NMR stacked spectra of 1-bromo-10-undecene, 1-azido-10-undecene, 1 amino-10-undecene and bis-unsaturated amide (5) in $\mathrm{CDCl}_{3}$.

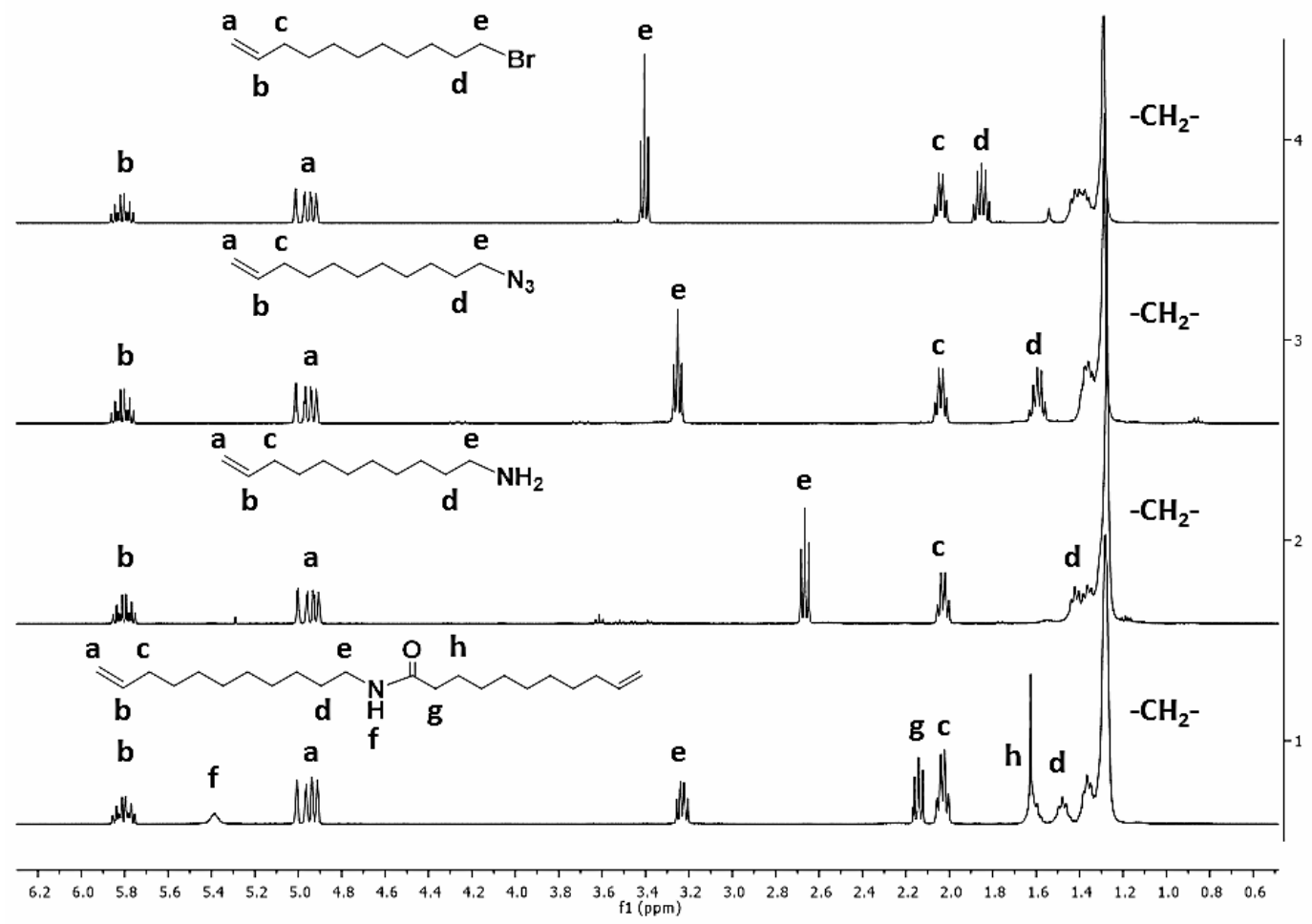

Figure S13-DSC 2nd heating curves of (a) polyurethane, (b) polyester and (c) poly(esterurethane)- $10^{\circ} \mathrm{C} . \mathrm{min}^{-1}$. 


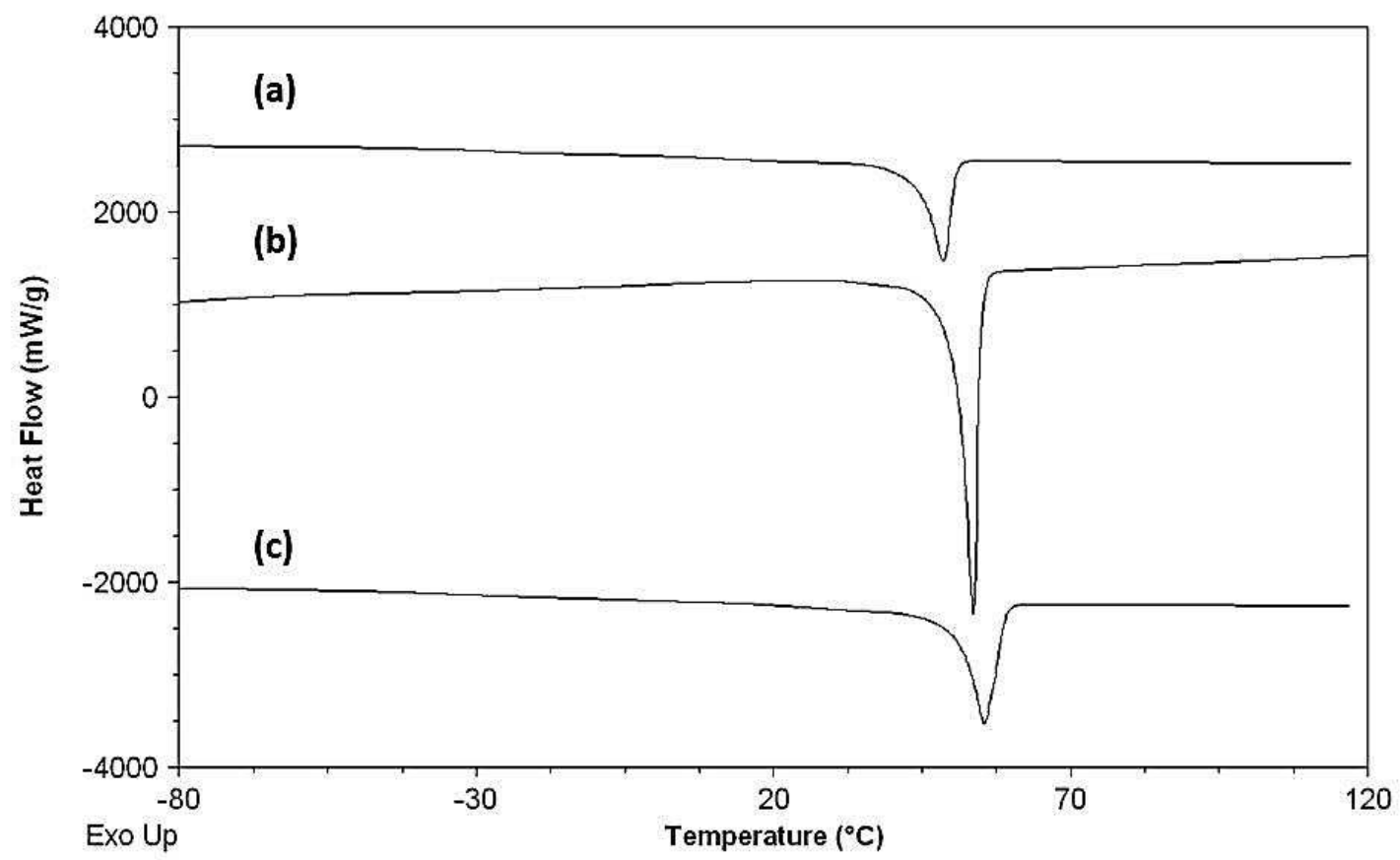

- 16 - 